\title{
Zinc oxide nanoparticles conjugated with clinically-approved medicines as potential antibacterial molecules
}

\author{
Noor Akbar ${ }^{1 \dagger}$, Zara Aslam² ${ }^{2 \dagger}$, Ruqaiyyah Siddiqui', Muhammad Raza Shah² and Naveed Ahmed Khan ${ }^{3 *}$
}

\begin{abstract}
At present, antibiotic resistance is one of the most pressing issues in healthcare globally. The development of new medicine for clinical applications is significantly less than the emergence of multiple drug-resistant bacteria, thus modification of existing medicines is a useful avenue. Among several approaches, nanomedicine is considered of potential therapeutic value. Herein, we have synthesized Zinc oxide nanoparticles (ZnO-NPs) conjugated with clinically-approved drugs (Quercetin, Ceftriaxone, Ampicillin, Naringin and Amphotericin B) with the aim to evaluate their antibacterial activity against several Gram-positive (Methicillin resistant Staphylococcus aureus, Streptococcus pneumoniae and Streptococcus pyogenes) and Gram-negative (Escherichia coli K1, Serratia marcescens and Pseudomonas aeruginosa) bacteria. The nanoparticles and their drug conjugates were characterized using UV-visible spectrophotometry, dynamic light scattering, Fourier transform infrared spectroscopy and atomic force microscopy. Antibacterial activity was performed by dilution colony forming unit method and finally 3-(4,5-dimethylthiazole-2-yl)-2,5-diphenyltetrazolium bromide (MTT) assays were performed to determine their cytotoxic effects against human cell lines. ZnO-NPs revealed maxima surface plasmon resonance band at 374 and after conjugation with beta-cyclodextrin at $379 \mathrm{~nm}$, polydispersity with size in range of 25-45 nm with pointed shaped morphology. When conjugated with ZnO-NPs, drug efficacy against MDR bacteria was enhanced significantly. In particular, Ceftriaxone- and Ampicillin-conjugated ZnO-NPs exhibited potent antibacterial effects. Conversely, ZnO-NPs and drugs conjugated NPs showed negligible cytotoxicity against human cell lines except Amphotericin B (57\% host cell death) and Amphotericin B-conjugated with ZnO-NPs (37\% host cell death). In conclusion, the results revealed that drugs loaded on ZnO-NPs offer a promising approach to combat increasingly resistant bacterial infections.
\end{abstract}

Keywords: Antibiotic resistance, Infectious diseases, ZnO-nanoparticles, Cytotoxicity

\section{Key points}

- Zinc oxide nanoparticles were conjugated successfully with several medicines.

- ZnO-NPs-conjugated drugs exhibited potent cidal effects against MDR bacteria.

\footnotetext{
*Correspondence: naveed5438@gmail.com

${ }^{\dagger}$ Noor Akbar and Zara Aslam contributed equally to this work

${ }^{3}$ Department of Clinical Sciences, College of Medicine, University

of Sharjah, University City, 27272 Sharjah, United Arab Emirates

Full list of author information is available at the end of the article
}

- Human cells were not affected by ZnO-NPs and drugs conjugated NPs.

- Nanomedicine hold promise in the treatment of infections caused by MDR bacteria.

\section{Introduction}

The emergence and spread of drug-resistant microbes is far more rapid than the introduction of new medicines into clinical practice (Ling et al. 2015). In recent decades, the list of multiple drug-resistant (MDR) bacteria have grown at an alarming rate associated with a growing list 
of infections, such as pneumonia, tuberculosis, diarrhea, septicemia, gonorrhoea, meningitis etc. (Khameneh et al. 2016). In part, this is due to significant genetic flexibility observed in bacteria that enable them to respond to wide-ranging ecological threats, especially wider use of antibacterial compounds in animal feed and to treat routine infections without prescription (Blair et al. 2015; Munita and Arias 2016). The discovery and introduction of novel antibacterial agents in the clinical practice is a lengthy and expensive process. An alternative approach is to modify existing drugs to enhance their efficacy. In this regard, nanotechnology-based nanomedicine is a promising approach in eradicating bacterial infections (Mukheem et al. 2018; Ssekatawa et al. 2020). Nanoparticles (NPs) have demonstrated antibacterial activity against a variety of MDR bacteria by increasing the surface area, enhancing release of drug, reducing the dose required, and improving solubility and bioavailability of drugs (Wang et al. 2017; Anwar et al. 2018). Several nanoparticles have been tested as delivery vehicles comprising of dendrimers, liposomes, metallic nanoparticles, and polymeric nanoparticles. Metal nanoparticles have intrinsic physicochemical and optical properties, which enable them to be used for various applications (Souza et al. 2020). Notably, Zinc oxide NPs (ZnO-NPs) have been used on nano as well as microscale in different formulations and considered safe against human cells (Sirelkhatim et al. 2015). ZnO-NPs possess unique semiconducting properties, which is the main cause of their utilization in electronics and biomedical field. $\mathrm{ZnO}$-NPs have inherent antibacterial potential and has been declared as biocompatible antimicrobials by FDA (Souza et al. 2020). Moreover, ZnO-NPs are cost-effective and their ease of functionalization is highly feasible for the development of antibacterial formulations (Jones et al. 2008). Beta-cyclodextrins (BCDs) are biocompatible cyclic oligosaccharides having R-(1,4)-linked-Dglucopyranose units arranged in ring form. BCDs have unique ability to form inclusion complexes with organic molecules via host-guest interactions and hence widely utilized in drug delivery applications (suitable drug carriers) for the enhancement of solubility and bioavailability of poor water-soluble drugs (Davis and Brewster 2004; Ren et al. 2017).

To determine whether ZnO-NPs exhibit antibacterial effects against MDR bacteria and whether conjugation of ZnO-NPs can enhance efficacy of drugs, several drugs were used. These include Quercetin (molar mass $302.2 \mathrm{~g} \mathrm{~mol}^{-1}$ ), a plant-based flavonoid with antibacterial activity. It showed bacteriostatic effects against $P$. aeruginosa, E. coli, S. enterica and S. aureus (Wang et al. 2018). Ceftriaxone (molar mass $554.6 \mathrm{~g} \mathrm{~mol}^{-1}$ ) belong to cephalosporin family with potent antibacterial properties
(Ebrahimi et al. 2020). It is used to treat a wide-range of bacterial infections including; meningitis, intraabdominal, middle ear, joint, bone and skin infections respectively (Kumar et al. 2016). Ceftriaxone kill bacteria by inhibiting the cross-linking of peptidoglycan and ultimately stop cell wall synthesis (Hathout et al. 2020). Ampicillin (molar mass $349.41 \mathrm{~g} \mathrm{~mol}^{-1}$ ), a beta lactam antibacterial drug is used to treat infections caused by Gram-positive and Gram-negative bacteria. Ampicillin inhibit the transpeptidases needed in cell wall synthesis followed by bacterial cell lysis (Tipper 1985; Kaushik et al. 2014). Naringin (580.541 $\mathrm{g} \mathrm{mol}^{-1}$ ) is a flavonoid used to target the quorum sensing mechanism and inhibit Aeromonas hydrophila (Srinivasan et al. 2020). Amphotericin $\mathrm{B}$ (molar mass $924.079 \mathrm{~g} \mathrm{~mol}^{-1}$ ) is used as effective antifungal that inhibits the formation of cell walls of young fungal cells (Grela et al. 2019).

In the present study, ZnO-NPs were synthesized by direct precipitation method and after successful formation the NPs were loaded with beta-cyclodextrin and finally conjugated with different drugs to form $\mathrm{ZnO}-\mathrm{CD}$ Drug complex. The NPs itself and their conjugates were characterized by several characterization techniques such as zeta sizer and zeta potential analysis, UV-visible, FTIR and AFM. Furthermore, the NPs and drug-NPs conjugates were evaluated for their antibacterial activities against Gram-positive and Gram-negative MDR bacteria. Finally, their cytotoxicity/viability were assessed using human cell lines. The conjugation of drugs with $\mathrm{ZnO}$ NPs exhibited remarkable antibacterial activities with minimal human cells cytotoxicity. These are remarkable findings and should pave the way in the formulations of new antibacterials.

\section{Materials and methods}

Zinc acetate dihydrate, sodium hydroxide, beta-cyclodextrin (BCD), quercetin (QT) and naringin (NAR) were purchased from Sigma-Aldrich. Ceftriaxone (CFT), ampicillin (AMP) and amphotericin (AMB) were acquired from Merck. HPLC-grade methanol and acetone were used. Deionized water was used for making solutions. All chemicals were utilized without pre-treatment or further purification.

\section{Preparation of $\mathrm{ZnO}$ nanoparticles (ZnO NPs)}

Zinc oxide nanoparticles were synthesized by utilizing zinc acetate dihydrate and $\mathrm{NaOH}$ as precursors using direct precipitation method as previously described (Raoufi 2013; Ghorbani et al. 2015). Aqueous solutions of zinc acetate dehydrate $(0.1 \mathrm{M})$, and sodium hydroxide $(0.2 \mathrm{M})$ were prepared. Both solutions were added drop wise into a beaker at room temperature with continuous stirring at $600 \mathrm{rpm}$ for $2 \mathrm{~h}$. The resulting white 
precipitation was separated by centrifugation (Minispin Plus, Eppendorf ${ }^{\circledR}$ ) for $15 \mathrm{~min}$ at $10,000 \times g$ and subsequently washed three times with deionized water followed by acetone washing. The precipitates were dried in oven at $120^{\circ} \mathrm{C}$ for $6 \mathrm{~h}$ and then calcinated at $300^{\circ} \mathrm{C}$ in air atmosphere to obtain stable $\mathrm{ZnO}-\mathrm{NPs}$.

\section{Preparation of beta-cyclodextrin capped $\mathrm{ZnO}$ nanoparticles (BCD-ZnO NPs)}

For the preparation of BCD-ZnO NPs complex, $30 \mathrm{mg}$ of $\mathrm{ZnO}$ nanoparticles were dispersed in $10 \mathrm{~mL}$ of deionized water and sonicated for $15 \mathrm{~min}$. Next, $30 \mathrm{mg}$ betacyclodextrin was dissolved in $10 \mathrm{~mL}$ of deionized water and stirred at $600 \mathrm{rpm}$ for $10 \mathrm{~min}$ to obtain a transparent solution. Both solutions were mixed under continuous stirring at $600 \mathrm{rpm}$. After six hours, beta-cyclodextrin capped $\mathrm{ZnO}$ nanoparticles ( $\mathrm{ZnO}-\mathrm{BCD} \mathrm{NPs}$ ) were separated by centrifugation (Minispin Plus, Eppendorf ${ }^{\circledR}$ ) for $15 \mathrm{~min}$ at $8000 \times g$ and washed three times with deionized water. The supernatant was freeze-dried, and the residue weighed, which indicated that beta-cyclodextrin capped $\mathrm{ZnO}$ nanoparticles contained about $30.5 \%$ by weight of beta-cyclodextrin. Beta-cyclodextrin capped $\mathrm{ZnO}$ nanoparticles (BCD-ZnO NPs) were dried in oven below $80{ }^{\circ} \mathrm{C}$.

\section{Preparation of drug-loaded beta-cyclodextrin capped $\mathrm{ZnO}$} nanoparticles (ZnO-BCD NPs)

Five $\mathrm{mL}$ solution of five drugs (Quercetin, naringin, ceftriaxone, ampicillin and amphotericin B) was prepared potential analysis. The particle size, size distribution and zeta potential of $\mathrm{ZnO}$ nanoparticles ( $\mathrm{ZnO} \mathrm{NPs}$ ), betacyclodextrin capped $\mathrm{ZnO}$ nanoparticles (BCD-ZnO NPs) and drug loaded BCD-ZnO NPs was determined by dynamic light scattering (DLS) (Malvern, Zetasizer Nano ZSP) as described previously (Yusof et al. 2019). Sample was prepared in deionized water, passed through syringe filter $(0.45 \mu \mathrm{m})$ and analyzed for size, poly dispersity index (PDI) and zeta potential determination. FTIR spectra of ZnO NPs, BCD-ZnO NPs and drug loaded BCD-ZnO NPs were recorded by Shimadzu IR-470 spectrometer (Shimadzu, Kyoto) in the range of $4000-400 \mathrm{~cm}^{-1}$ by using $\mathrm{KBr}$ disk method as described earlier (Yusof et al. 2019). Sample was grinded with $\mathrm{KBr}$ $1 \%(\mathrm{w} / \mathrm{w})$ and pressed by applying mechanical pressure to obtain $\mathrm{KBr}$ disk.

\section{Drug encapsulation efficiency of ZnO-BCD NPs}

Five drugs (Quercetin, naringin, ceftriaxone, ampicillin and amphotericin $\mathrm{B}$ ) were separately loaded on to $\mathrm{ZnO}$ BCD NPs (Additional file 1: Figure S1). Approximately $5 \mathrm{mg}$ of $\mathrm{ZnO}-\mathrm{BCD}$ NPs were suspended in $5 \mathrm{~mL}$ of methanol containing each drug $(1 \mathrm{mg} / \mathrm{mL})$. The resulting suspension was stirred $(600 \mathrm{rpm})$ at room temperature for $24 \mathrm{~h}$. Drug loaded ZnO-BCD NPs were collected by centrifugation and the supernatant was analyzed by using UV-visible spectrophotometer (Shimadzu, UV-1800) for the evaluation of amount of un-encapsulated drug. The encapsulation efficiency of drug loaded ZnO-BCD NPs was calculated by the given formula.

$$
\text { Drug encapsulation efficiency }=\frac{\text { Total amount of drug }- \text { Free drug in the supernatant }}{\text { Total amount of drug }} \times 100
$$

in methanol having concentration $1 \mathrm{mg} / \mathrm{mL} .5 \mathrm{mg} \mathrm{ZnO-}$ BCD NPs were added in each five-drug solutions separately upon continuous stirring at $600 \mathrm{rpm}$. After $24 \mathrm{~h}$, the suspension was centrifuged (Minispin Plus, Eppendorf $\left.^{\circledR}\right)$ at $8000 \times g$ for $15 \mathrm{~min}$ to obtain drug (Quercetin, naringin, ceftriaxone, ampicillin and amphotericin $\mathrm{B}$ ) loaded beta-cyclodextrin capped $\mathrm{ZnO}$ nanoparticles. Drug loaded nanoparticles were dried at room temperature and suspended in deionized water for further characterization.

\section{Characterization of ZnO NPs, BCD-ZnO NPs and drug loaded BCD-ZnO NPs}

$\mathrm{ZnO}$ nanoparticles ( $\mathrm{ZnO} \mathrm{NPs}$ ), beta-cyclodextrin capped $\mathrm{ZnO}$ nanoparticles (BCD-ZnO NPs) and drug loaded $\mathrm{BCD}-\mathrm{ZnO}$ NPs were characterized with UV-visible spectroscopy, Fourier transform infrared spectroscopy (FTIR), Atomic Force Microscopy, zeta sizer and zeta

\section{Bacterial cultures}

Bacterial cultures used in the study are shown in (Table 1). The bacteria include methicillin resistant Staphylococcus aureus (MRSA), Streptococcus pyogenes and S. penumoniae (Gram-positive), Escherichia coli K1, Pseudomonas aeruginosa and Serratia marcescens

Table 1 Bacterial isolates used in this study

\begin{tabular}{ll}
\hline Bacterial isolate & Strain \\
\hline Methicillin resistant Staphylococcus aureus & MTCC 381123 (clinical isolate) \\
Streptococcus pyogenes & ATCC 49399 (clinical isolate) \\
Streptococcus pneumoniae & ATCC 13883 (clinical isolate) \\
Pseudomonas aeruginosa & ATCC 10145 (clinical isolate) \\
Escherichia coli K1 & MTCC 710859 (clinical isolate) \\
Serratia marcescens & MTCC 13880 (clinical isolate) \\
\hline
\end{tabular}


(Gram-negative). All the bacterial isolated were cultured and revived at $37{ }^{\circ} \mathrm{C}$ for overnight prior the experiments.

\section{Antibacterial assays}

Antibacterial assays were performed to determine the bactericidal activities of the drugs and drug conjugated nanoparticles (Table 2) against a panel of Gram-positive and Gram-negative bacteria as previously described (Akbar et al. 2018, 2020). Briefly, $1 \times 10^{6}$ bacterial cells were incubated with $100 \mu \mathrm{g} / \mathrm{mL}$ of the drugs and drug conjugated NPs for $2 \mathrm{~h}$ at $37^{\circ} \mathrm{C}$. Next, the cultures were serially diluted ten-fold and different dilutions (i.e., $10^{-3}-10^{-6}$ ) were plated on freshly prepared nutrient agar plates. The plates were incubated for overnight at $37^{\circ} \mathrm{C}$ and the viable bacterial colonies were enumerated. For negative control, bacteria alone were incubated in saline whereas, bacteria incubated with $100 \mu \mathrm{g} / \mathrm{mL}$ of Gentamicin was taken as positive control.

Next, minimum inhibitory concentration $\left(\mathrm{MIC}_{50}\right)$ of $\mathrm{ZnO}$ and drugs loaded NPs was determined using broth micro-dilution assays as previously described (EmamiKarvani and Chehrazi 2011; Tamboli and Lee 2013). Briefly, $1 \times 10^{5}$ bacteria were incubated with $\mathrm{ZnO}-\mathrm{NP}$
NPs and drug-NPs conjugates that inhibited 50\% of growth of test bacteria was measured as $\mathrm{MIC}_{50}$.

\section{Cell viability assays}

Cell viability assays were performed to determine the cytotoxic properties of the drugs and drug-loaded NPs against human cell lines using 3-(4,5-dimethylthiazol2-yl)-2,5-diphenyltetrazolium bromide or MTT assays as described earlier (Anitha et al. 2018; Akbar et al. 2019). Briefly, cell lines were grown in a 96 well plates for overnight at $37{ }^{\circ} \mathrm{C}$ in the presence of $5 \% \mathrm{CO}_{2}$ in a humidified incubator. Upon 80-90\% confluency, the cell monolayer was challenged with a range of concentration (12.5, 25, $50,100,200$ and $400 \mu \mathrm{g} / \mathrm{mL}$ ) of the drugs and drug conjugates at $37{ }^{\circ} \mathrm{C}$ in the presence of $95 \%$ humidity and $5 \%$ $\mathrm{CO}_{2}$ for $24 \mathrm{~h}$. After this incubation, $10 \mu \mathrm{L}$ of freshly made MTT solution was added to each well and further incubated for $4 \mathrm{~h}$. Next, $100 \mu \mathrm{L}$ of DMSO was added to each well to dissolve the formazan crystals formed by the live cells. For negative control, DMSO was added to the well with no drug. Finally, the absorbance was recorded at $540 \mathrm{~nm}$ and values were interpreted to calculate the percentage inhibition/viability by following equation:

Mean $O D$ of test sample/MeanOD of negative control $\times 100$

and drugs loaded $\mathrm{ZnO}-\mathrm{NPs}$ at various concentrations ranging from 6.25 to $800 \mu \mathrm{g} / \mathrm{mL}$ (two-fold diluted in Muller Hinton Broth) at $37^{\circ} \mathrm{C}$ for overnight. Bacteria alone in $\mathrm{MHB}$ was used as positive control while $\mathrm{MHB}$ alone was used as negative control. After this incubation, $\mathrm{MIC}_{50}$ was calculted by measuring the optical density at $600 \mathrm{~nm}$ using Tecan plate reader. The lowest concentration of

\section{Statistical analysis}

For statistical analysis, GraphPad Prism version 8.0.2 (GraphPad Software, San Diego, CA, USA) was used. The data are expressed as the mean \pm standard error of several independent experiments performed in duplicates. $\mathrm{P}$ values were calculated using Student's T test (two-tailed

Table 2 Concentration of drugs and drug loaded $\mathrm{ZnO}-\mathrm{NPs}$ used in this study

\begin{tabular}{llll}
\hline S. no. & $\begin{array}{l}\text { Sample code of pure drug/ } \\
\text { formulation }\end{array}$ & Pure drug/formulation & $\begin{array}{c}\text { Concentration } \\
\boldsymbol{\mu g} / \mathbf{m L}\end{array}$ \\
\hline 1 & QTG & Quercetin & 100 \\
2 & CEFT & Ceftriaxone & 100 \\
3 & NAR & Naringin & 100 \\
4 & AMB & Amphotericin B & 100 \\
5 & AMPI & Ampicillin & 100 \\
6 & ZnO-CD & ZnO-cyclodextrin conjugate nanoparticles & 100 \\
7 & Zn-O & ZnO-nanoparticle & 100 \\
8 & CD & Beta-cyclodextrin & 100 \\
9 & ZnO-CD-AMPI & ZnO-cyclodextrin-Ampicillin conjugates & 100 \\
10 & ZnO-CD-CFT & ZnO-cyclodextrin-CFT conjugates & 100 \\
11 & ZnO-CD-NAR & ZnO-cyclodextrin-Naringin conjugates & 100 \\
12 & ZnO-CD-AMB & ZnO-cyclodextrin-Amphotericin B conjugates & 100 \\
13 & ZnO-CD-QTG & ZnO-cyclodextrin-Quercetin conjugates & 100 \\
\hline
\end{tabular}



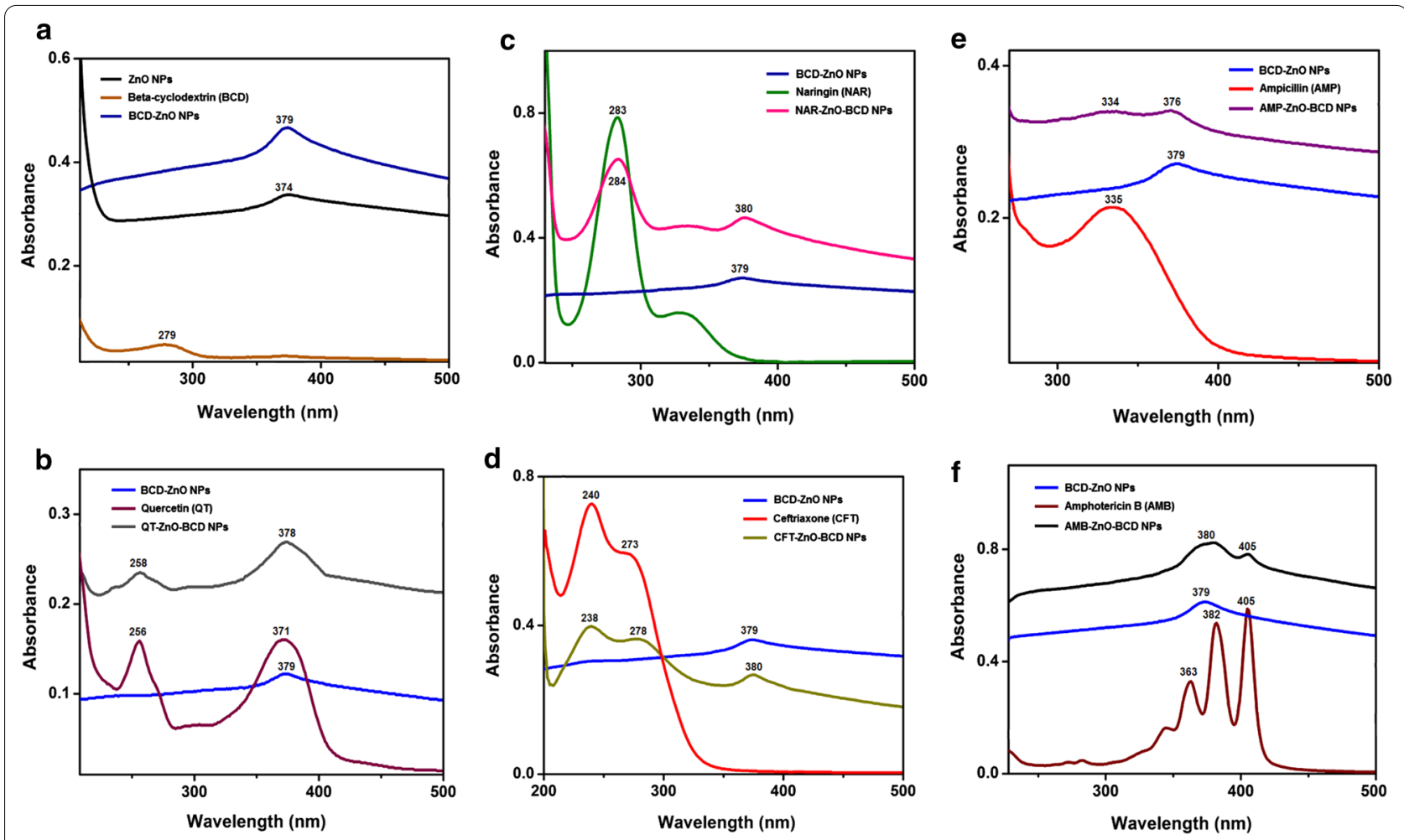

Fig. 1 Representing the UV-visible absorption spectra of nanoparticle, reducing/capping agent and different drugs conjugates. a Represents UV spectra of ZnO NPs, beta-cyclodextrin (BCD) and BCD-ZnO NPs, $\mathbf{b}$ showing spectra of BCD-ZnO NPs, quercetin and QT-BCD-ZnO NPs, $\mathbf{c}$ absorption spectra of BCD-ZnO NPs, naringin and NAR-BCD-ZnO NPs, $\mathbf{d}$ absorption spectra of BCD-ZnO NPs, ceftriaxone and CFT-BCD-ZnO NPs, e absorption spectra of BCD-ZnO NPs, ampicillin and AMP-BCD-ZnO NPs and $\mathbf{f}$ illustrating absorption spectra of BCD-ZnO NPs, amphotericin B and AMB-BCD-ZnO NPS

distribution) where P value $\leq 0.05$ was considered as statistically significant.

\section{Result}

UV-Visible absorption spectra of ZnO NPs and BCD-ZnO NPs and drug-BCD-ZnO NPs

UV-visible spectroscopic analysis was performed to evaluate the changes occurred in the UV-visible absorption of ZnO NPs after capping of beta-cyclodextrin over their surface (Fig. 1). UV-visible absorption spectrum of $\mathrm{ZnO}$ nanoparticles (black), beta-cyclodextrin (orange) and beta-cyclodextrin capped $\mathrm{ZnO}$ NPs (ZnO-BCD NPs, blue) is shown in (Fig. 1a). The absorption peak at $374 \mathrm{~nm}$ is the characteristic peak for hexagonal wurtzite $\mathrm{ZnO}$. Beta-cyclodextrin exhibited peak at $279 \mathrm{~nm}$. After the capping of $\mathrm{ZnO}$ NPs with beta-cyclodextrin, the UVvisible absorbance of $\mathrm{ZnO}-\mathrm{BCD}$ NPs red shifted towards $379 \mathrm{~nm}$, which indicated the interaction of beta-cyclodextrin with $\mathrm{ZnO}$ NPs surface causes defects in the crystal lattice of $\mathrm{ZnO}$-NPs due to the presence of beta-cyclodextrin atoms in the lattice. Similarly, UV-Vis spectra for all the five drugs conjugated with ZnO-BCD NPs are shown in (Fig. 1b-f) confirming the successful interaction of drugs and ZnO-BCD NPs (Kadam et al. 2020). Quercetin exhibited two major peaks around $256 \mathrm{~nm}$ and $371 \mathrm{~nm}$ which are associated with the cinnamoyl and benzoyl systems present in the basic structure of QT (Catauro et al. 2015). After the loading of quercetin (Fig. 1b), QT$\mathrm{ZnO}-\mathrm{BCD}$ NPs showed peaks at $258 \mathrm{~nm}$ and $378 \mathrm{~nm}$, the peak at $378 \mathrm{~nm}$ is broadened which might be due to the merging of peaks of benzoyl system of QT and BCD-ZnO NPs. Naringin absorption peak appeared at $283 \mathrm{~nm}$ corresponding to the cinnamoyl system (Diaz-Uribe et al. 2016; Fig. 1c) while after the formation of NAR-ZnOBCD NPs, two peaks appeared at $284 \mathrm{~nm}$ and $380 \mathrm{~nm}$ which are the characteristics peaks of naringin and BCD-ZnO NPs. Ceftriaxone absorption peak appeared at $240 \mathrm{~nm}$ (Ethiraj et al. 2014, Fig. 1d) and CFT-ZnOBCD NPs showed peaks at 238 and $380 \mathrm{~nm}$. Absorption peak of ampicillin appeared at $335 \mathrm{~nm}$ (Ambekar et al. 2015) while AMP-ZnO-BCD NPs showed two peaks at $334 \mathrm{~nm}$ and $376 \mathrm{~nm}$ (Fig. 1e). Amphotericin B showed three characteristic peaks at $363 \mathrm{~nm}, 382 \mathrm{~nm}$ and $405 \mathrm{~nm}$ (Vandermeulen et al. 2006) while after the formation of AMB-ZnO-BCD NPs, two peaks appeared at $380 \mathrm{~nm}$ and $405 \mathrm{~nm}$ (Fig. 1f). Calibration curve are shown for 
quercetin (Additional file 1: Figure S2), naringin (Additional file 1: Figure S3), ceftriaxone (Additional file 1: Figure S4), ampicillin (Additional file 1: Figure S5), and amphotericin B (Additional file 1: Figure S6).

\section{Size distribution and zeta potential analysis of ZnO NPs and BCD-ZnO NPs}

Particle size distribution of nanocarriers plays a major role for the design of drug delivery systems. It has been reported that particle size affects the pattern of drug release (Liu et al. 2015). Smaller particles have larger surface area which leads to optimum loading of drug as compared to particles having larger size distribution. Zeta sizer analysis was carried out for the evaluation of average particle size of $\mathrm{ZnO}$ nanoparticles $(\mathrm{ZnO}$ NPs) and beta-cyclodextrin capped ZnO NPs (BCD$\mathrm{ZnO}$ NPs). The results are presented in Fig. 2. The average particle size of $\mathrm{ZnO}$ NPs was found in the range of 15-25 nm (Fig. 2) having polydispersity index (PDI) 0.101 . This result showed that the $\mathrm{ZnO}$ nanoparticles are highly monodisperse and have uniform size range (Kavitha et al. 2017). After the capping of beta-cyclodextrin over the surface of $\mathrm{ZnO}$ nanoparticles the average particle size distribution of BCD-ZnO NPs increased and was found to be in the range of $25-45 \mathrm{~nm}$ with PDI 0.103 (Fig. 2). The increased polydispersity of nanoparticles lead to increase in size distribution of nanoparticles due to the surface interaction of beta-cyclodextrin with $\mathrm{ZnO}$ NPs. Surface charges present on the nanoparticles are important as they determine the interaction of nanocarriers with the biological environment as well as their behavior with bioactive compounds. Zeta potential analysis was carried out for the evaluation of surface charges and stability of $\mathrm{ZnO}$ nanoparticles ( $\mathrm{ZnO}-\mathrm{NPs}$ ) and betacyclodextrin capped ZnO NPs (BCD-ZnO NPs). Zeta potential graph of $\mathrm{ZnO}-\mathrm{NPs}$ and $\mathrm{BCD}-\mathrm{ZnO}$ NPs are shown in (Fig. 3). Zeta potential of $\mathrm{ZnO}$ nanoparticles was found to be -5.2 and BCD-ZnO NPs was -9.7 . This increase in zeta potential indicated that the interaction of beta-cyclodextrin with $\mathrm{ZnO}$ nanoparticles causes enhancement in the surface charges and lead to greater stability of BCD-ZnO NPs. Higher surface charges on nanoparticles prevents aggregation of formulation due to greater repulsion among the nanoparticles. The result of dynamic light scattering (DLS) analysis of ZnO NPs and BCD-ZnO NPs are summarized in Table 3.

Five drugs (Quercetin, naringin, ceftriaxone, ampicillin and amphotericin B) were separately loaded over the surface of $\mathrm{ZnO}-\mathrm{NPs}$ by following the procedure explained in the experimental section (Additional file 1: Figure S1). After the drug loading, zeta sizer and zeta potential analysis was carried out to observe the changes occurred in particle size and surface charges on drug loaded BCD-ZnO NPs nanoparticles. The results are summarized in the Table 3 . As expected, the size and zeta potential of the nanoparticles after the loading of drug increases as shown in Table 3 (Kaur et al. 2019). Surface charges tends to increase due to the interaction of drug molecules with the surface of BCD-ZnO NPs.

\section{FTIR analysis}

Comparative FTIR spectra of $\mathrm{ZnO}$ nanoparticles $(\mathrm{ZnO}$ NPs), beta-cyclodextrin (BCD) and beta-cyclodextrin capped $\mathrm{ZnO}$ nanoparticles ( $\mathrm{ZnO}-\mathrm{BCD} \mathrm{NPs}$ ) is shown in (Fig. 4a-f). FTIR of $\mathrm{ZnO}$ nanoparticles (black) showed broad peak in the region of $3400-3300 \mathrm{~cm}^{-1}$ which corresponds to the $\mathrm{O}-\mathrm{H}$ bond while insignificant peak at $1638 \mathrm{~cm}^{-1}$ might be due to the acetate group, precursor used for the synthesis of $\mathrm{ZnO}$ nanoparticles (Nagaraju et al. 2017; Fig. 4a). Significant peak in the region of $550-400 \mathrm{~cm}^{-1}$ is the characteristic peak at of $\mathrm{Zn}-\mathrm{O}$ bond pessent in the $\mathrm{ZnO}$ nanoparticles (Nagaraju et al. 2017). Beta-cyclodextrin FTIR spectrum (orange) showed broad peak in the region of $3500-3300 \mathrm{~cm}^{-1}$ which is the characteristic peak of $\mathrm{O}-\mathrm{H}$ group while peak at $2929 \mathrm{~cm}^{-1}$ correspond to the stretching frequency of $\mathrm{C}-\mathrm{H}$ bond (Rachmawati et al. 2013). IR absorption peaks at $1646 \mathrm{~cm}^{-1}, 1156 \mathrm{~cm}^{-1}$, $976 \mathrm{~cm}^{-1}$ and $853 \mathrm{~cm}^{-1}$ are attributed to the $\mathrm{H}-\mathrm{O}-\mathrm{H}$, $\mathrm{C}-\mathrm{O}, \mathrm{C}-\mathrm{O}-\mathrm{C}$ (glucose units) and $\mathrm{C}-\mathrm{O}-\mathrm{C}$ bond of rings of beta-cyclodextrin, respectively (Reddy et al. 2020). FTIR spectrum (blue) of beta-cyclodextrin capped $\mathrm{ZnO}$ nanoparticles ( $\mathrm{ZnO}-\mathrm{BCD} \mathrm{NPs}$ ) showed broad peak in the region of $3500-3200 \mathrm{~cm}^{-1}$ which is the characteristic peak of $\mathrm{O}-\mathrm{H}$ groups while a significant characteristic absorption peak at $1635 \mathrm{~cm}^{-1}$ is appearing due to $\mathrm{H}-\mathrm{O}-\mathrm{H}$ bond of beta-cyclodextrin. Peaks at $1154 \mathrm{~cm}^{-1}, 942 \mathrm{~cm}^{-1}$ and $857 \mathrm{~cm}^{-1}$ are appearing due to the $\mathrm{C}-\mathrm{O}, \mathrm{C}-\mathrm{O}-\mathrm{C}$ (glucose units) and $\mathrm{C}-\mathrm{O}-\mathrm{C}$ bond of beta-cyclodextrin attached over the surface of $\mathrm{ZnO}-\mathrm{BCD}$ NPs. Most significant peak in the region of $550-400 \mathrm{~cm}^{-1}$ corresponds to the $\mathrm{Zn}-\mathrm{O}$ bond (Sawant and Bamane 2018). Appearance and slight shift of beta-cyclodextrin peaks in the FTIR speactrum of $\mathrm{ZnO}-\mathrm{BCD} \mathrm{NPs}$, confirms the successful capping of $\mathrm{ZnO}$ with beta-cyclodextrin (Fig. 4a). After loading of all five drugs (Quercetin, naringin, ceftriaxone, ampicillin and amphotericin B) over beta-cyclodextrin capped $\mathrm{ZnO}$ nanoparticles ( $\mathrm{ZnO}-\mathrm{BCD} \mathrm{NPs}$ ), FTIR analysis was performed to observe possible interactions of functional groups of each drug with ZnO-BCD NPs. The results are shown in (Figs. 2f-4b). The FTIR spectrum of quercetin exhibited broad peak at $3409 \mathrm{~cm}^{-1}$ due to the phenolic hydroxyl groups $(-\mathrm{OH})$ while band at $1666 \mathrm{~cm}^{-1}$ is due to the carbonyl $(\mathrm{C}=\mathrm{O})$ stretching frequency (Catauro et al. 2015; Fig. 4b). Absorption peaks 
A
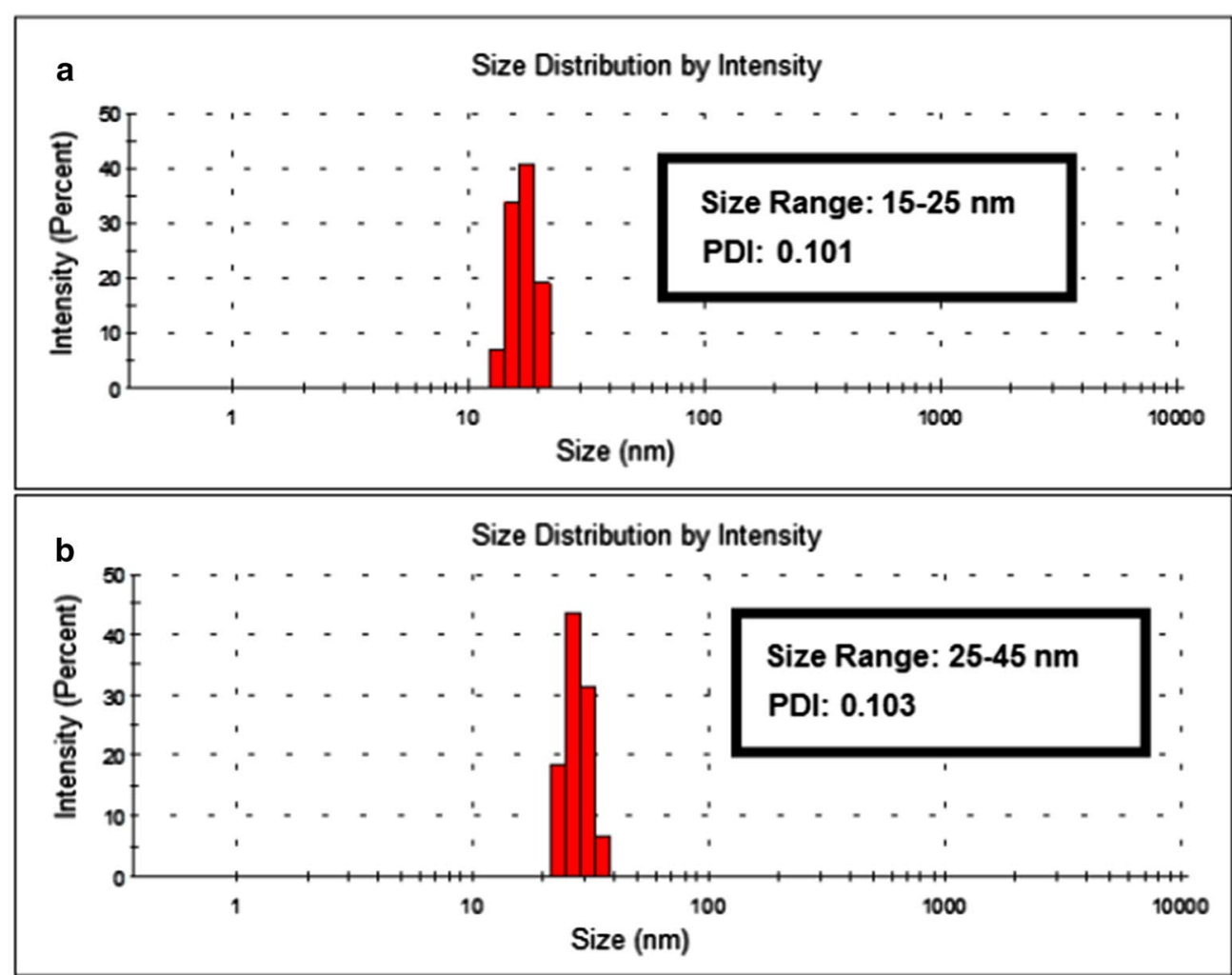

B

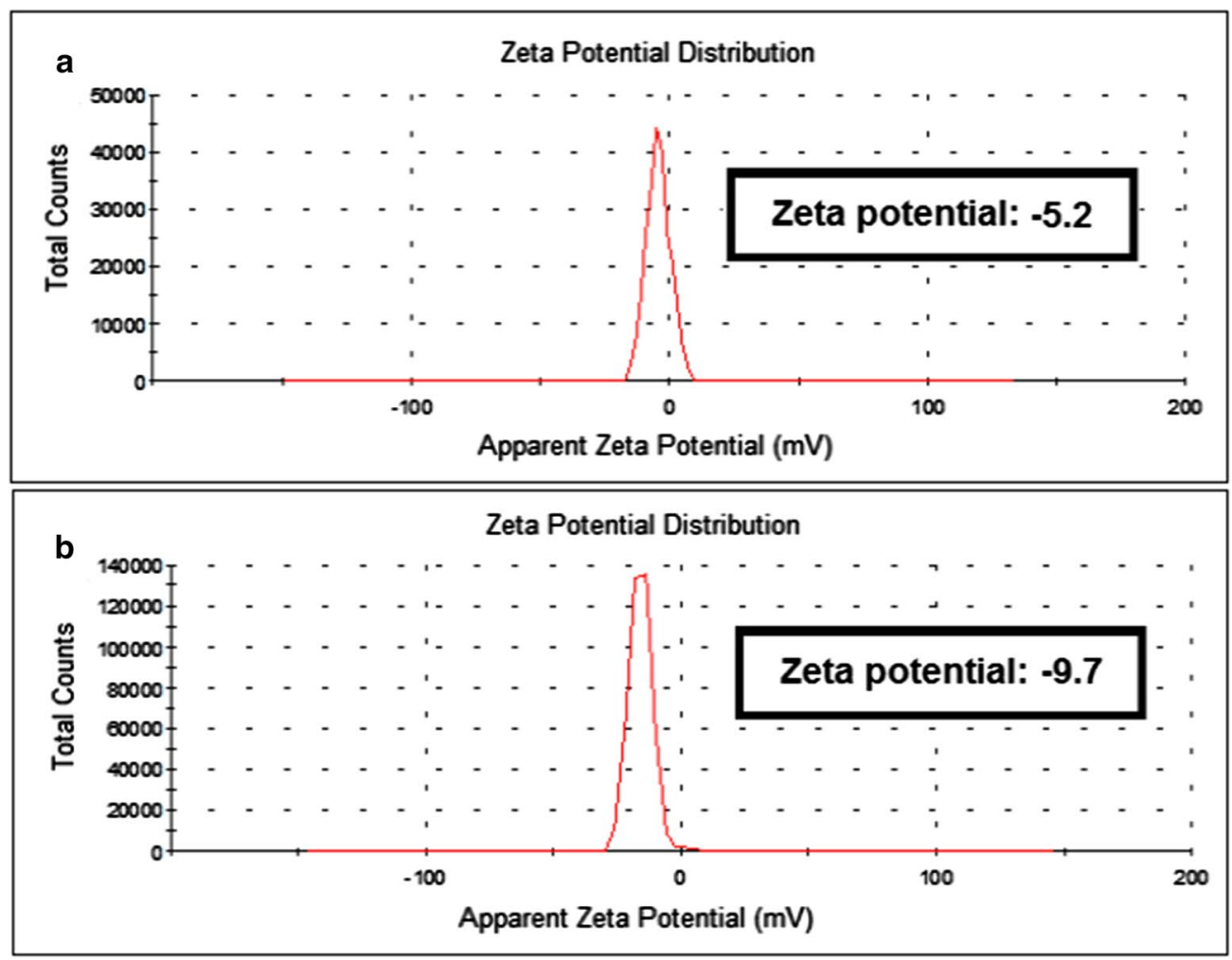

Fig. 2 Showing the average particle size distribution histogram and zeta potential of ZnO nanoparticle and the reducing/capping agent $\mathbf{A}$ depicts average particle size distribution a ZnO nanoparticles (ZnO NPs) and $\mathbf{b}$ beta-cyclodextrin capped ZnO NPs (ZnO-BCD NPs) and $\mathbf{B}$ showing zeta potential graph of $\mathbf{a} \mathrm{ZnO}$ nanoparticles ( $\mathrm{ZnO} \mathrm{NPs}$ ) and $\mathbf{b}$ beta-cyclodextrin capped $\mathrm{ZnO}$ NPs (ZnO-BCD NPs) 

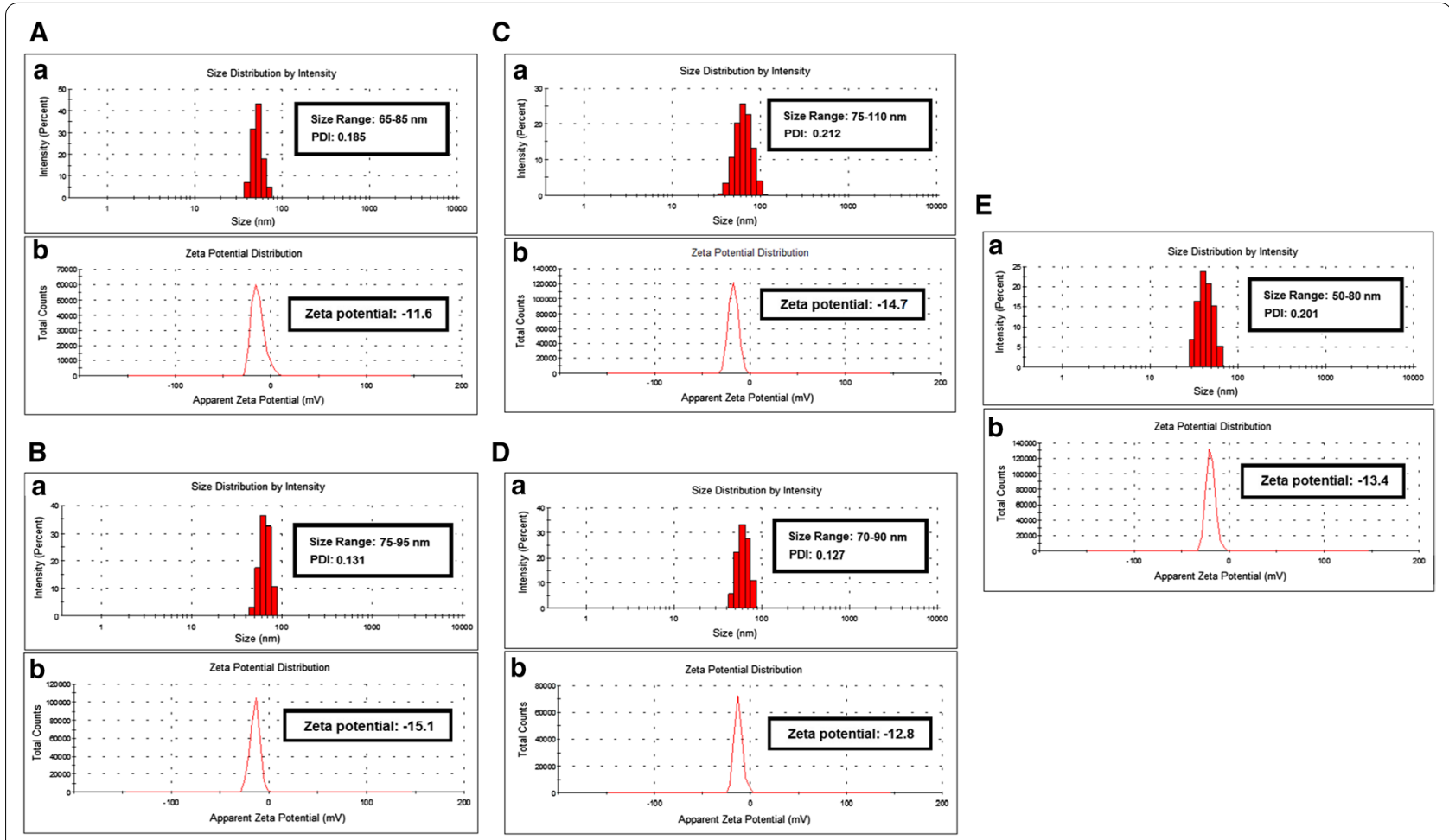

Fig. 3 Illustrating the average particle size distribution histogram and zeta potential of $\mathrm{ZnO}$ nanoparticle, the reducing/capping agent and various drugs used in the study where $\mathbf{A}$ showing particle size (a) and zeta potential graph (b) of quercetin loaded beta-cyclodextrin capped ZnO NPs (QT-ZnO-BCD NPs), B showing particle size distribution histogram (a) and zeta potential graph (b) of naringin loaded beta-cyclodextrin capped ZnO NPs (NAR-ZnO-BCD NPs), C display average particle size distribution histogram (a) and zeta potential graph (b) of ceftriaxone loaded beta-cyclodextrin capped ZnO NPs (CFT-ZnO-BCD NPs), D display particle size distribution histogram (a) and zeta potential graph (b) of ampicillin loaded beta-cyclodextrin capped ZnO nanoparticles (AMP-ZnO-BCD NPs) and $\mathbf{E}$ showing particle size distribution histogram (a) and zeta potential graph (b) of amphotericin B loaded beta-cyclodextrin capped ZnO nanoparticles (AMB-ZnO-BCD NPs)

Table 3 Size, size distribution, zeta potential of ZnO NPs and BCD-ZnO NPs and encapsulation efficiency of drug (quercetin, naringin, ceftriaxone, ampicillin and amphotericin B) loaded BCD-ZnO NPs

\begin{tabular}{|c|c|c|c|c|c|}
\hline S. no. & Nanoparticles (NPs) & Size range $(\mathrm{nm})$ & $\begin{array}{l}\text { Polydispersity Index } \\
\text { (PDI) }\end{array}$ & $\begin{array}{l}\text { Zeta potential } \\
(\mathrm{mV})\end{array}$ & $\begin{array}{l}\text { Drug } \\
\text { encapsulation } \\
\text { efficiency (EE\%) }\end{array}$ \\
\hline 1 & $\mathrm{ZnONPs}$ & $15-25$ & 0.101 & -5.2 & - \\
\hline 2 & BCD-ZnO NPs & $25-45$ & 0.103 & -9.7 & - \\
\hline 1 & QT-ZnO-BCD NPs & $65-85$ & 0.185 & -11.6 & 52.5 \\
\hline 2 & NAR-ZnO-BCD NPs & $75-95$ & 0.131 & -15.1 & 44.5 \\
\hline 3 & CFT-ZnO-BCD NPs & $75-110$ & 0.212 & -14.7 & 47.5 \\
\hline 4 & AMP-ZnO-BCD NPs & $70-90$ & 0.127 & -12.8 & 40.0 \\
\hline 5 & AMB-ZnO-BCD NPs & $50-80$ & 0.201 & -13.4 & 49.5 \\
\hline
\end{tabular}

at $1610 \mathrm{~cm}^{-1}$ and $1562 \mathrm{~cm}^{-1}$ are the characteristic $\mathrm{C}=\mathrm{C}$ aromatic stretch bands. Peaks at $1263 \mathrm{~cm}^{-1}$ and $1013 \mathrm{~cm}^{-1}$ are appearing due to the stretching vibrations of $\mathrm{C}-\mathrm{O}-\mathrm{C}$ and $\mathrm{C}=\mathrm{C}-\mathrm{O}$ bonds, respectively (Catauro et al. 2015). The FTIR spectrum of QT-ZnO-BCD NPs showed peak in the region of $3500-3300 \mathrm{~cm}^{-1}$ which is due to the $-\mathrm{OH}$ group (Sathishkumar et al.
2021) while broad peak at $1636 \mathrm{~cm}^{-1}$ indicated the merging of peaks of quercetin $\mathrm{C}=\mathrm{C}$ aromatic bonds and beta-cyclodextrin $\mathrm{H}-\mathrm{O}-\mathrm{H}$ bending vibrations. Suppression of peaks was observed at $1554 \mathrm{~cm}^{-1}$, $1269 \mathrm{~cm}^{-1}$ and $1031 \mathrm{~cm}^{-1}$ which are attributed to $\mathrm{C}=\mathrm{C}, \mathrm{C}-\mathrm{O}-\mathrm{C}$ and $\mathrm{C}=\mathrm{C}-\mathrm{O}$ bonds, respectively. Major absorption peak in the region of $550-400 \mathrm{~cm}^{-1}$ 

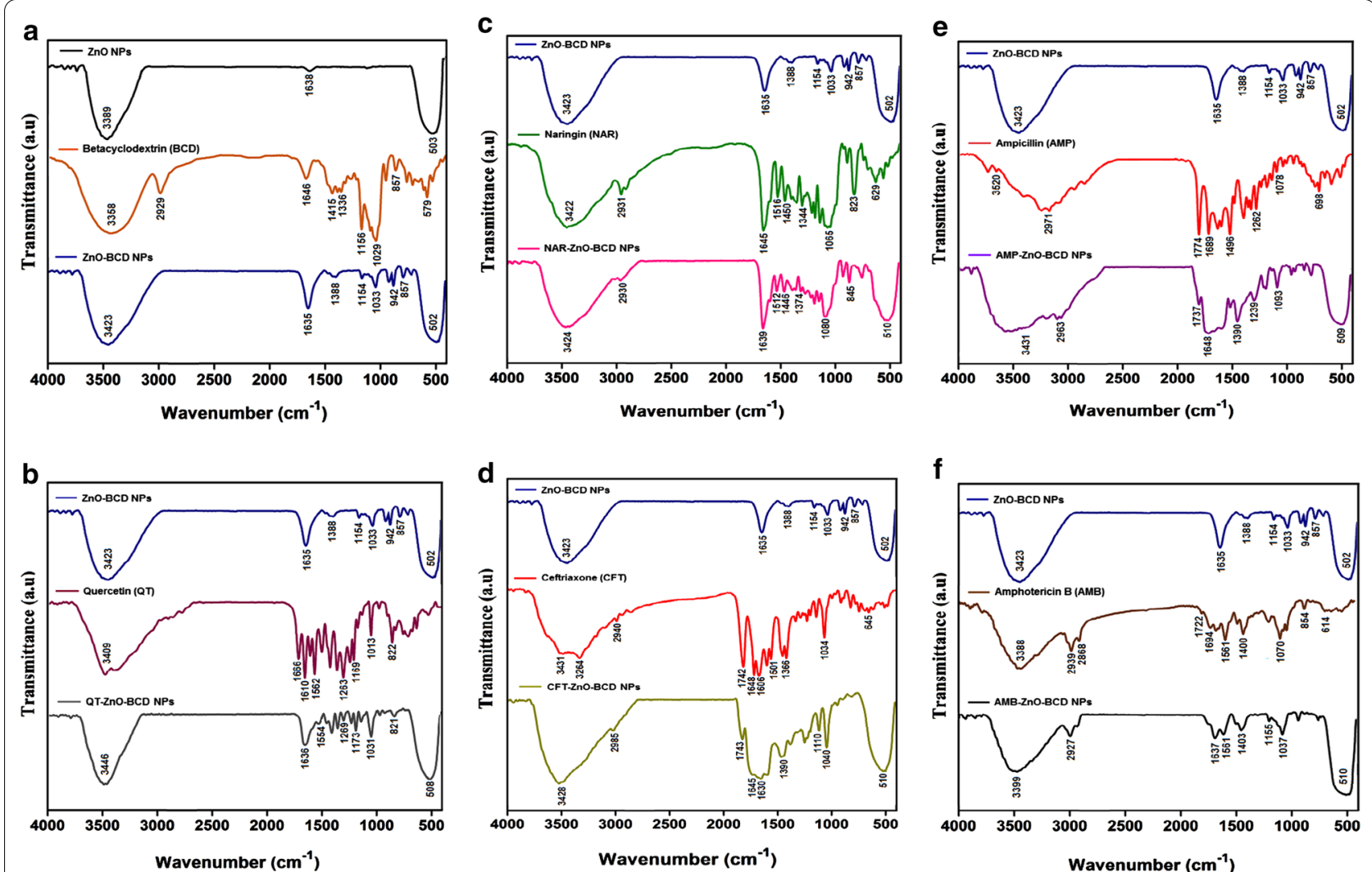

Fig. 4 a FT-IR spectra of ZnO-NPs alone is compared with BCD and BCD-ZnO-NPs complex, $\mathbf{b}$ relative FT-IR analysis of (ZnO-BCD NPs), quercetin (QT) and (QT-ZnO-BCD NPs), c comparative FTIR analysis of (ZnO-BCD NPs), naringin (NAR) and (NAR-ZnO-BCD NPs), $\mathbf{d}$ FTIR analysis of (ZnO-BCD NPs), ceftriaxone (CFT) and (CFT-ZnO-BCD NPs), e FTIR analysis of (ZnO-BCD NPs), ampicillin (AMP) and (AMP-ZnO-BCD NPs) and $\mathbf{f} F T I R$ analysis of (ZnO-BCD NPs), amphotericin B (AMB) and (AMB-ZnO-BCD NPs). All the spectra were acquired by employing IR-470 spectrometer (Shimadzu, Kyoto, Japan)

is attributed to the $\mathrm{Zn}-\mathrm{O}$ bond (Sathishkumar et al. 2021). The peak shifting and suppression indicated the interaction of functional groups of quercetin with $\mathrm{ZnO}-\mathrm{BCD}$ NPs and formation of QT-ZnO-BCD NPs (Fig. 4b).

After loading of Naringin over the surface of $\mathrm{ZnO}-\mathrm{BCD}$ NPs, the FTIR spectra of NAR-ZnO-BCD NPs showed broad peak in the region of $3500-3300 \mathrm{~cm}^{-1}$ corresponding to the $-\mathrm{OH}$ group while peak at $2930 \mathrm{~cm}^{-1}$ is due to the stretching vibration of $\mathrm{C}-\mathrm{H}$ bond (Yang et al. 2020) (Fig. 4c). Shifting of peaks was observed at $1639 \mathrm{~cm}^{-1}$ and $1446 \mathrm{~cm}^{-1}$ which are attributed to the stretching frequencies of $\mathrm{C}=\mathrm{O}$ and $-\mathrm{C}=\mathrm{C}-$ (aromatic) bond. Peak at $1080 \mathrm{~cm}^{-1}$ is the stretching vibration of $-\mathrm{C}-\mathrm{O}-$ (polyols) groups of Naringin in NAR-ZnO-BCD NPs (Yang et al. 2020). The peak shifting observed in the absorption frequencies of $\mathrm{C}=\mathrm{O}$ and $-\mathrm{C}-\mathrm{O}$ - bond indicated the interaction of these functional groups with the surface of ZnO-BCD NPs (Fig. 4c).

The characteristic peaks of ceftriaxone appeared at $3431 \mathrm{~cm}^{-1}$ and $3264 \mathrm{~cm}^{-1}$ that corresponds to the asymmetric and symmetric stretching frequency of $\mathrm{N}-\mathrm{H}$ group while absorption band at $2940 \mathrm{~cm}^{-1}$ is due to the stretching vibration of $\mathrm{C}-\mathrm{H}$ group (Gunasekaran and Charles 2008; Fig. 4d). The stretching vibrations at $1742 \mathrm{~cm}^{-1}, 1648 \mathrm{~cm}^{-1}$ and $1606 \mathrm{~cm}^{-1}$ corresponds to carbonyl of $\beta$-lactam $(C=O)$, carbonyl of amide $(C=O)$ and $\mathrm{C}=\mathrm{N}$ bond of oxime, respectively (Gunasekaran and Charles 2008). The peak at $1034 \mathrm{~cm}^{-1}$ is due to the stretching vibration of $\mathrm{C}-\mathrm{O}$ group. The broad peak for CFT-ZnO-BCD NPs in the region of $3500-3300 \mathrm{~cm}^{-1}$ and $2985 \mathrm{~cm}^{-1}$ shows $\mathrm{O}-\mathrm{H}$ and $\mathrm{C}-\mathrm{H}$ group, correspondingly (Mushtaq et al. 2017). Suppression of peak at $1743 \mathrm{~cm}^{-1}$ indicated the interaction of carbonyl $(\mathrm{C}=\mathrm{O})$ of $\beta$-lactam with the surface of BCD-ZnO NPs. Presence of peak at 1645-1608 $\mathrm{cm}^{-1}$ related to vibrational frequencies of carbonyl of amide $(\mathrm{C}=\mathrm{O}), \mathrm{C}=\mathrm{N}$ bond of oxime and $\mathrm{H}-\mathrm{O}-\mathrm{H}$ of $\mathrm{BCD}$, respectively (Mushtaq et al. 2017). Peak $550-400 \mathrm{~cm}^{-1}$ is the characteristic peak of $\mathrm{Zn}-\mathrm{O}$ bond. Suppression and shifting of peaks of ceftriaxone confirms the successful loading of drug over the surface of BCD-ZnO NPs (Fig. 4d). 
FTIR of ampicillin showed broad peak in the region of $3500-3200 \mathrm{~cm}^{-1}$ which is due to the hydroxyl group, also the shoulder speaks at $3347 \mathrm{~cm}^{-1}$ and $3358 \mathrm{~cm}^{-1}$ are due to the primary amine $\mathrm{NH}_{2}$ stretches (Khatoon et al. 2019; Fig. 4e). Absorption peaks at $1764 \mathrm{~cm}^{-1}$ and $1668 \mathrm{~cm}^{-1}$ are attributed to the stretching frequencies of carbonyl of $\beta$-lactam $(\mathrm{C}=\mathrm{O})$ and carbonyl of amide $(\mathrm{C}=\mathrm{O})$, respectively (Khatoon et al. 2019). Absorption peaks appearing at $1457 \mathrm{~cm}^{-1}$ and $1164 \mathrm{~cm}^{-1}$ corresponds to the stretching frequencies of $\mathrm{C}=\mathrm{C}$ and $\mathrm{C}-\mathrm{O}$ bonds (Khatoon et al. 2019). FTIR spectrum for BCD-ZnO NPs, exhibited peak in the region of $3500-3200 \mathrm{~cm}^{-1}$, which corresponds to the $\mathrm{O}-\mathrm{H}$ group. Suppressed peak at $1747 \mathrm{~cm}^{-1}$ corresponding to the stretching frequency of carbonyl of $\beta$-lactam $(\mathrm{C}=\mathrm{O})$ was observed. Merging of peaks occurred in the region of $1668-1500 \mathrm{~cm}^{-1}$ which is due to the carbonyl of amide $(\mathrm{C}=\mathrm{O})$ of ampicillin and $\mathrm{H}-\mathrm{O}-\mathrm{H}$ bond of beta-cyclodextrin. Peak shifting was observed at $1454 \mathrm{~cm}^{-1}$ and $1132 \mathrm{~cm}^{-1}$ which corresponds to the stretching frequencies of $\mathrm{C}=\mathrm{C}$ and $\mathrm{C}-\mathrm{O}$ bonds. Broad peak appeared in the region of 550 $400 \mathrm{~cm}^{-1}$ which is due to the stretching vibration of $\mathrm{Zn}-\mathrm{O}$ bond. The increase in peak intensity and shifting of peaks indicates the interaction of ampicillin with $\mathrm{ZnO}$ BCD NPs (Fig. 4e).

Amphotericin B FTIR spectrum showed peak in the region of $3500-3200 \mathrm{~cm}^{-1}$ due to the $-\mathrm{OH}$ groups (Gagoś andArczewska 2010; Fig. 4f). Peaks at $2939 \mathrm{~cm}^{-1}$ and $2868 \mathrm{~cm}^{-1}$ are the $\mathrm{C}-\mathrm{H}$ stretching frequencies. Peaks at $1722 \mathrm{~cm}^{-1}$ and $1694 \mathrm{~cm}^{-1}$ shows stretching vibrational frequencies of carbonyl $(\mathrm{C}=\mathrm{O})$ of ester and carboxylic acid. Sharp peak at $1561 \mathrm{~cm}^{-1}, 1172 \mathrm{~cm}^{-1}$ and $1070 \mathrm{~cm}^{-1}$ corresponds to the stretching vibrations of $\mathrm{C}=\mathrm{C}$, $\mathrm{C}-\mathrm{O}-\mathrm{C}$ and $\mathrm{C}-\mathrm{O}$ bonds of amphotericin $\mathrm{B}$, respectively (Gagoś andArczewska 2010). Peak in the region of $3500-3200 \mathrm{~cm}^{-1}$ for AMP-ZnO-BCD NPs shows -OH group while peaks at $2927 \mathrm{~cm}^{-1}$ and $2856 \mathrm{~cm}^{-1}$ assigned to the $\mathrm{C}-\mathrm{H}$ stretching of amphotericin B (Kaur et al. 2019). Suppression of peaks was observed at $1718 \mathrm{~cm}^{-1}$ and $1690 \mathrm{~cm}^{-1}$ which indicated the interaction of carbonyl $(\mathrm{C}=\mathrm{O})$ of ester and carbonyl $(\mathrm{C}=\mathrm{O})$ of carboxylic acid. Absorption peak at $1640 \mathrm{~cm}^{-1}$ corresponds to the $\mathrm{H}-\mathrm{O}-\mathrm{H}$ bond of beta-cyclodextrin. Peaks at $1521 \mathrm{~cm}^{-1}$, $1182 \mathrm{~cm}^{-1}$ and $1037 \mathrm{~cm}^{-1}$ are due to the stretching vibrations of $\mathrm{C}=\mathrm{C}, \mathrm{C}-\mathrm{O}-\mathrm{C}$ and $\mathrm{C}-\mathrm{O}$ bonds of amphotericin $\mathrm{B}$, respectively (Fig. 4f). Appearance of peak in region $550-400 \mathrm{~cm}^{-1}$ confirm $\mathrm{Zn}-\mathrm{O}$ presence.

\section{AFM analysis}

For the evaluation of morphological changes over the surface of $\mathrm{ZnO}-\mathrm{BCD}$ NPs after loading of five drugs (Quercetin, naringin, ceftriaxone, ampicillin and amphotericin $\mathrm{B}$ ), atomic force microscopy was performed and the results are shown in Fig. 5a-g. The AFM image of bare $\mathrm{ZnO}$ nanoparticles exhibited pointed shaped nanoparticles (Kalaiselvi et al. 2016) with uniform distribution over mica surface having maximum height at $3.5 \mathrm{~nm}$ (Fig. 5a). After the coating of BCD, the particles became broader and maximum height increases to $4.5 \mathrm{~nm}$ (Fig. 5b). After drugs loading, shape of the nanoparticles changed significantly. QT-ZnO-BCD NPs exhibited spherical shaped nanoparticles, which are scattered over mica surface having height around $12.0 \mathrm{~nm}$ (Fig. 5c). NAR-ZnO-BCD NPs showed very ordered pointed shaped nanoparticles having $16.5 \mathrm{~nm}$ height (Fig. 5d). CFT-ZnO-BCD NPs and AMP-ZnO-BCD NPs showed broad dome shaped morphologies having maximum height around 7.5 and $19.0 \mathrm{~nm}$, respectively (Fig. 5e, f). AMB-ZnO-BCD NPs appeared as circular shaped nanoparticles having maximum height around $18.7 \mathrm{~nm}$ (Fig. 5g).

\section{ZnO-CD-drugs nanocomposite showed significant antibacterial activities against MDR pathogenic bacteria} ZnO-NPs, drugs alone (Quercetin, Ceftriaxone, Naringin, Amphotericin B and Ampicillin), and the combination of $\mathrm{ZnO}-\mathrm{CD}$-drug were tested for their antibacterial activities against a panel of Gram-negative and Grampositive pathogenic bacteria. The results revealed that drugs and drug conjugated $\mathrm{ZnO}$-NPs showed significant bactericidal activities against MRSA ( $\mathrm{P} \leq 0.05$; Fig. $6 \mathrm{a})$. ZnO-CD complex and cyclodextrin, NAR and AMB did not show antibacterial properties whereas, rest of the drugs and their NPs conjugates showed significant bactericidal effects against MRSA. Drug alone and drugNPs comparison showed that the NPs further enhance their bactericidal properties against MRSA. When tested against S. pyogenes, all the drugs and their NPs counterparts except CD exhibited antibacterial effects (Fig. 6b). When drug alone and their NPs was compared, there is no significant differences between the drug and their NPs for ceftriaxone and ampicillin. All drugs and their NPs except CD and NAR showed extraordinary antibacterial activities against S. pneumoniae (Fig. 6c).

Among Gram-negative bacteria, all drugs except $\mathrm{ZnO}$ CD, CD, QTG, NAR and its NPs, showed bactericidal activities against $P$. aeruginosa $(\mathrm{P} \leq 0.05$; Fig. 7a). More importantly, among all the drug-NPs conjugate $\mathrm{ZnO}$ CD-QTG showed bactericidal activities compared to its drug i.e., QTG. When tested against $E$. coli $\mathrm{K} 1$, all the drugs and their NPs except $\mathrm{ZnO}-\mathrm{CD}$ and $\mathrm{CD}$ alone presented bactericidal activities (Fig. 7b). In case of drugNPs comparison, all the NPs augments the antibacterial activity except ampicillin. For $S$. marcescens, all the drug except $C D$ revealed antibacterial properties. Moreover, the NPs exceptionally increases the antibacterial potency of the drugs (Fig. 7c). The $\mathrm{MIC}_{50}$ values of $\mathrm{ZnO}$-NPs and 

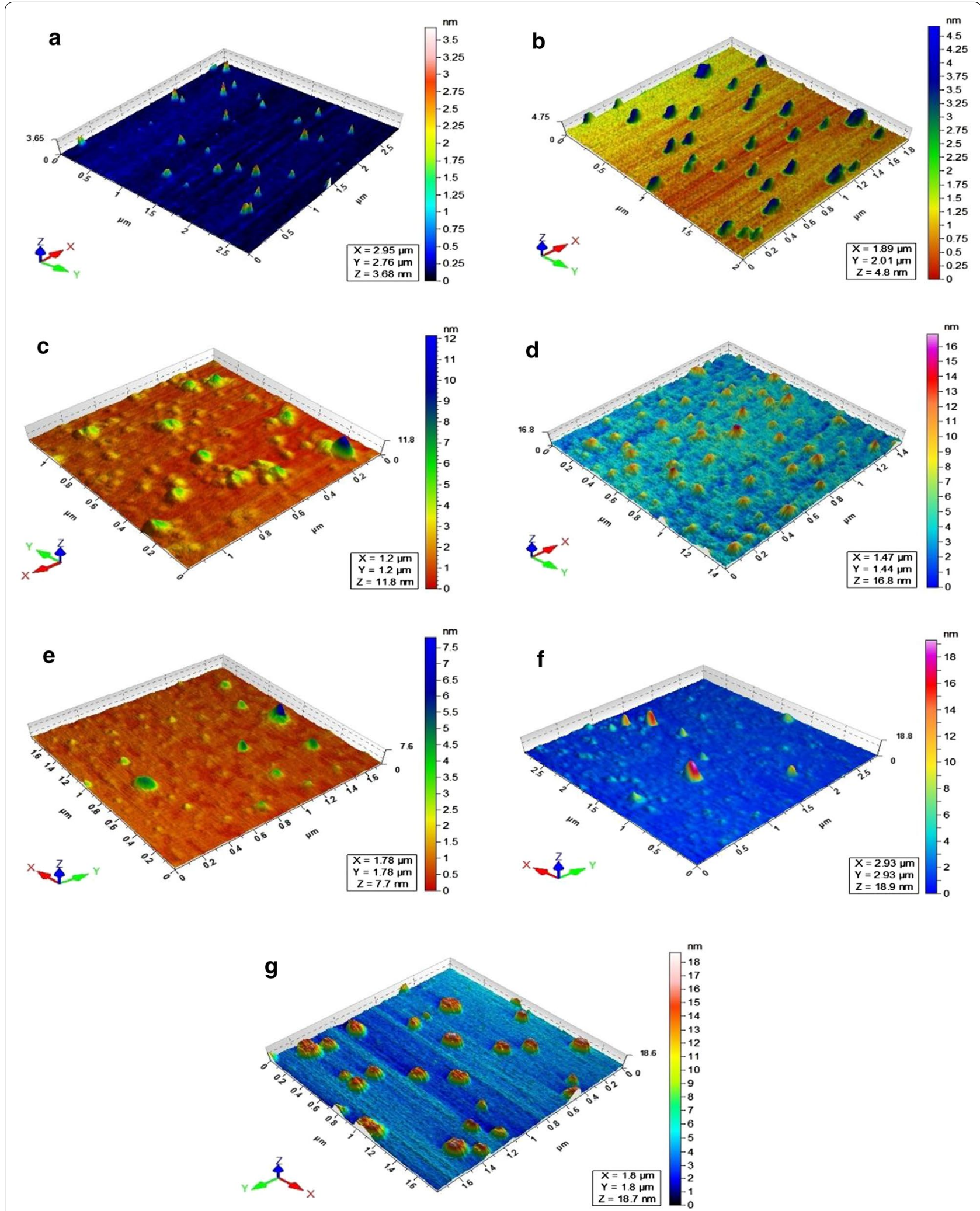

Fig. 5 Atomic force microscopic analysis of ZnO NPs and ZnO-BCD-NPs and drugs loaded ZnO-BCD-NPs. The AFM analysis showed that ZnO-NPs alone are pointed shaped (a) when conjugated with BCD, it becomes bigger in size (b) while after drug loading over the NPs surface, the shape as well as height of nanoconjugates was significantly increased showing the successful formation of drug-NPs conjugates (c-g) 

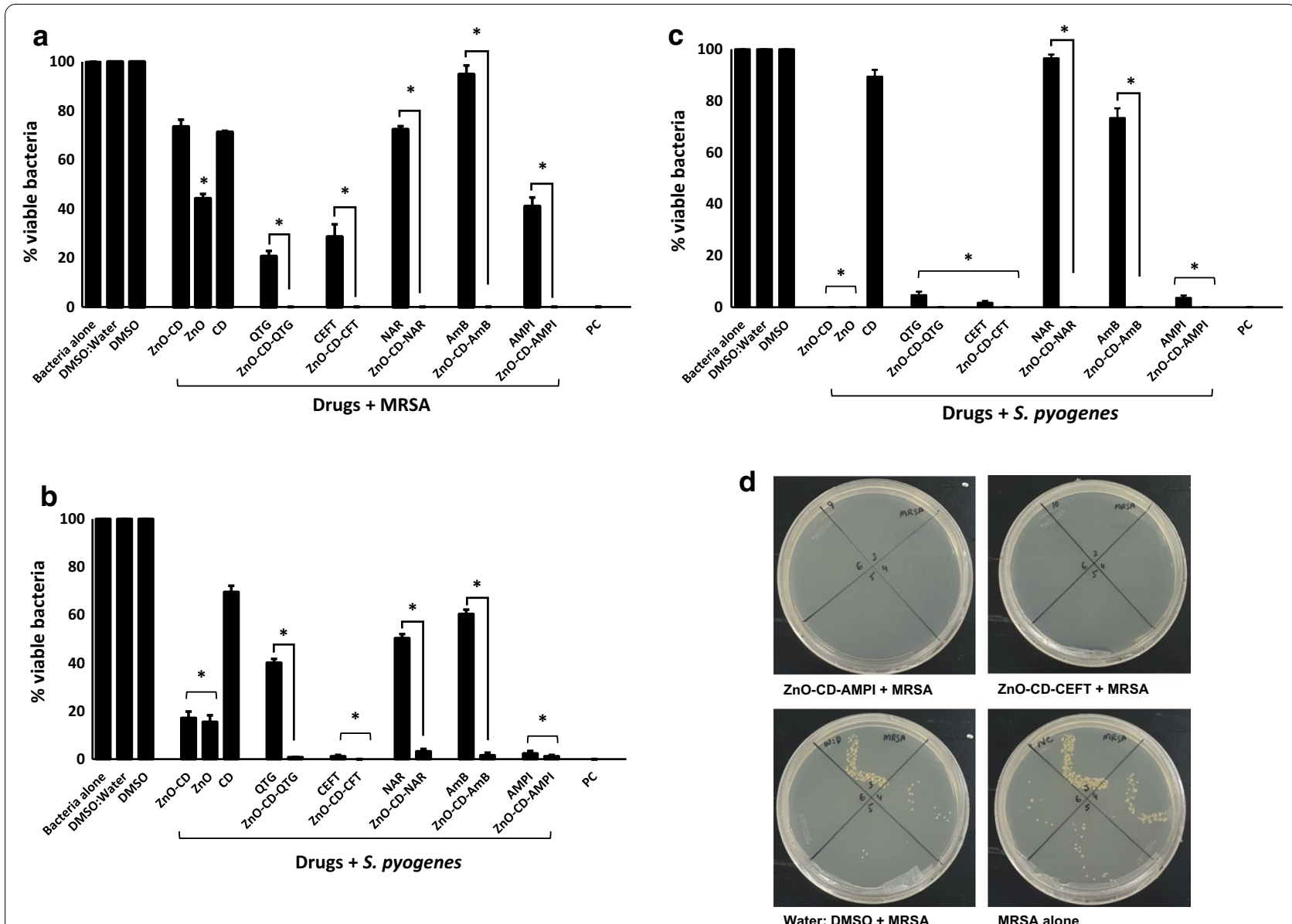

ZnO-CD-CEFT + MRSA

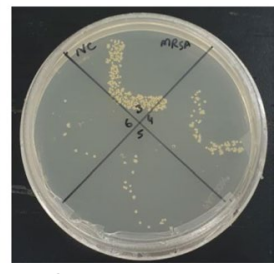

Fig. $6 \mathrm{ZnO}-\mathrm{NPs}$ loaded with various drugs showed important antibacterial activity against Gram-positive pathogenic bacteria. Briefly, bacteria $\left(1 \times 10^{6}\right)$ were incubated with different drugs conjugated with ZnO-NPs and nanoparticles alone for two hours at $37^{\circ} \mathrm{C}$ as defined in Materials and Methods. Next, the cultures were ten-fold serially diluted and plated onto the nutrient agar plates. The plates were incubated for $24 \mathrm{~h}$ at $37^{\circ} \mathrm{C}$ and enumerated the viable bacterial colonies on the next day. The results showed that drugs conjugated ZnO-NPs exhibited significant antibacterial activity against the Gram-positive bacteria. For negative control, bacteria were incubated in PBS alone whereas for positive control gentamicin $(100 \mu \mathrm{g} / \mathrm{mL})$ was used. The data are representative of several experiments performed in duplicate and expressed as the mean \pm standard error, where ${ }^{*}$ ) represent when $P \leq 0.05$

drug encapsulated $\mathrm{ZnO}-\mathrm{NPs}$ are summarized in Table 4. The overall results showed that $\mathrm{ZnO}$ and drug loaded NPs presented substantial antibacterial activity against the clinical isolates.

\section{ZnO-CD drug conjugates exhibited minimal cytotoxicity} Cytotoxic effects of drugs/drug-NPs on human cell lines were determined using MTT assays. The results showed that the majority of drugs/drug-NPs showed minimal cytotoxicity upon overnight incubation (Fig. 8). Amphotericin B and its NPs conjugates counterpart showed $57 \%$ and $37 \%$ (moderate to high) cytotoxic effects against human cells respectively.

\section{Discussion}

Nano-biotechnology is receiving considerable attention to design new antibacterials (Seil and Webster 2012). Silver NPs (AgNPs) are well known to exert broad spectrum antibaterial effects (Guzman et al. 2012; Tamboli and Lee 2013). Nanocomposite of AgNPs and reduced graphine oxide ( $\mathrm{rGO}$ ) displayed antibatecial activity against a range of bacteria including Proteus mirabilis, E. coli and S. aureus (Habash et al. 2014, 2017; Prasad et al. 2017). In additon to AgNPs, copper oxide (CuO) and $\mathrm{ZnO}$ NPs have shown promising antibacterial activities (Azam et al. 2012). Further, to enhance the efficacy of antibacterials, here we have synthesized $\mathrm{ZnO}$-NPs, 


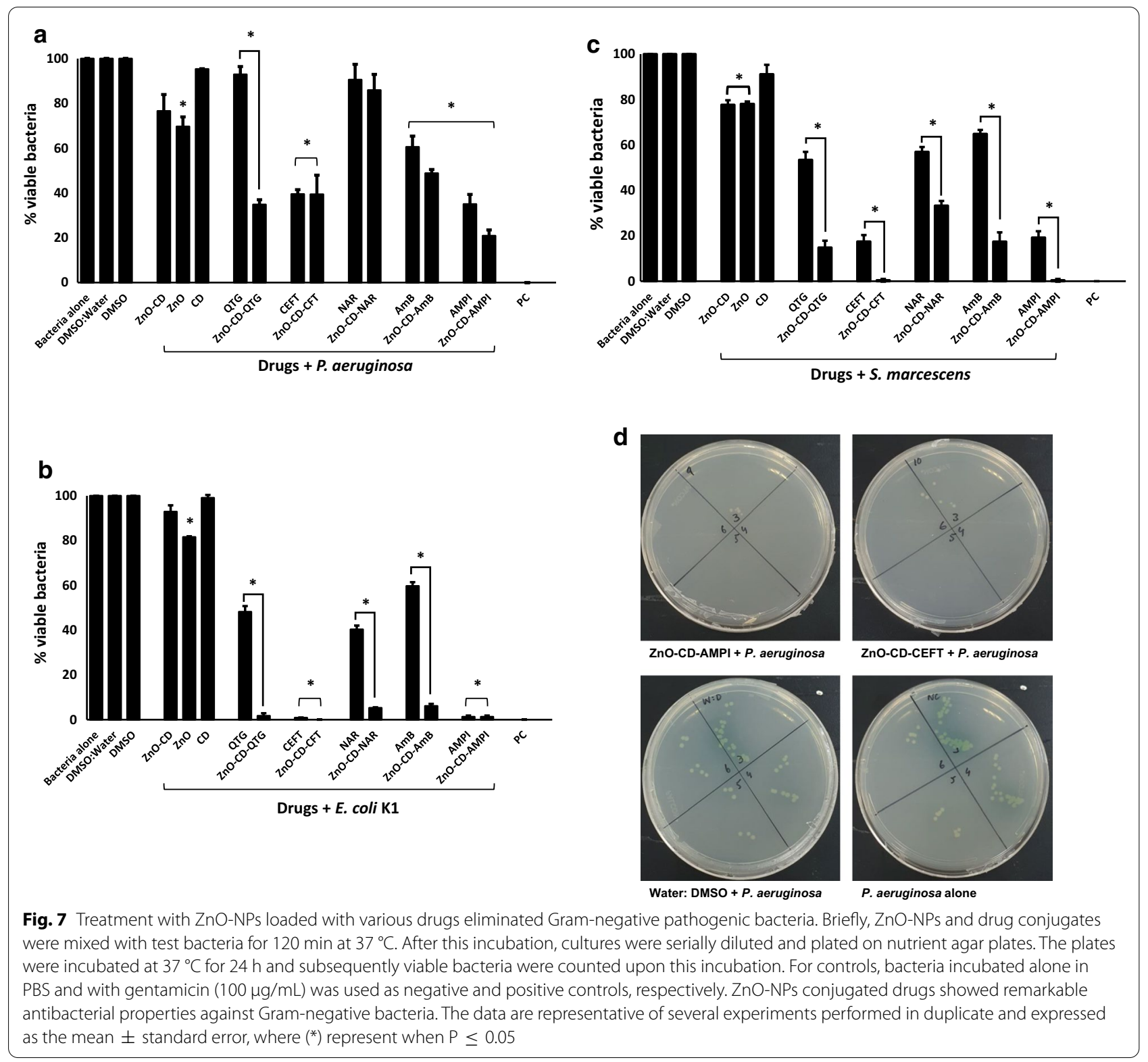

Table $4 \mathrm{MIC}_{50}(\mu \mathrm{g} / \mathrm{mL})$ of ZnO-NPs and drugs-loaded ZnO-NPs suspension against Gram-negative and Gram-positive bacteria

\begin{tabular}{lccccccccccc}
\hline Bacteria & $\begin{array}{l}\text { CEFT } \\
\mathbf{M I C}_{\mathbf{5 0}}\end{array}$ & $\begin{array}{l}\text { ZnO-CEFT } \\
\mathbf{M I C}_{\mathbf{5 0}}\end{array}$ & $\begin{array}{l}\text { QTG } \\
\mathbf{M I C}_{\mathbf{5 0}}\end{array}$ & $\begin{array}{l}\text { ZnO-QTG } \\
\mathbf{M I C}_{\mathbf{5 0}}\end{array}$ & $\begin{array}{l}\text { NAR } \\
\mathbf{M I C}_{\mathbf{5 0}}\end{array}$ & $\begin{array}{l}\text { ZnO-NAR } \\
\mathbf{M I C}_{\mathbf{5 0}}\end{array}$ & $\begin{array}{l}\text { AMB } \\
\mathbf{M I C}_{\mathbf{5 0}}\end{array}$ & $\begin{array}{l}\text { ZnO-AMB } \\
\mathbf{M I C}_{\mathbf{5 0}}\end{array}$ & $\begin{array}{l}\text { AMPI } \\
\mathbf{M I C}_{\mathbf{5 0}}\end{array}$ & $\begin{array}{l}\text { ZnO-AMPI } \\
\mathbf{M I C}_{\mathbf{5 0}}\end{array}$ & $\begin{array}{l}\text { ZnONPs } \\
\mathbf{M I C}_{\mathbf{5 0}}\end{array}$ \\
\hline E. colik1 & 23 & 14 & $>500$ & $>500$ & $>500$ & $>500$ & $>500$ & $>500$ & 123 & 64 & 290 \\
P. aeruginosa & 130 & 128 & $>500$ & 340 & $>500$ & $>500$ & $>500$ & 390 & 110 & 95 & 255 \\
S. marcescens & 55 & 19 & 310 & 245 & 350 & 275 & 470 & 325 & 56 & 21 & 245 \\
MRSA & 16 & 4 & 400 & 114 & $>500$ & 270 & $>500$ & 236 & 170 & 118 & 158 \\
S.pyogenes & 14 & 6 & 340 & 125 & 420 & 189 & 485 & 210 & 26 & 18 & 130 \\
S. pneumoniae & 11 & 4 & 90 & 55 & 88 & 52 & $>500$ & 270 & 22 & 9 & 95 \\
\hline
\end{tabular}




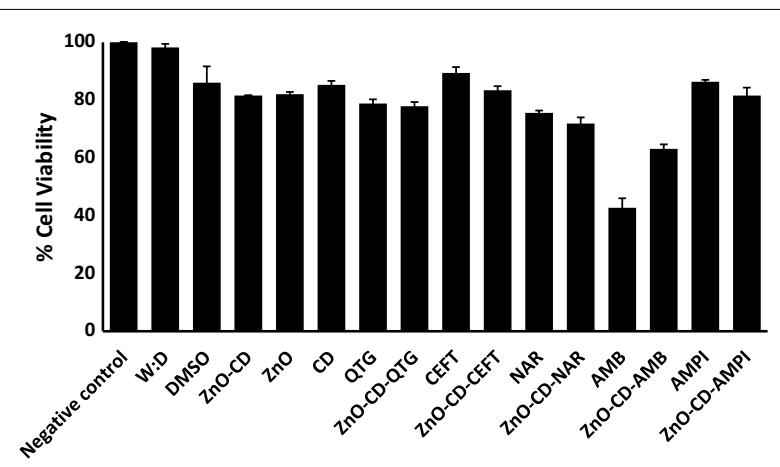

Fig. 8 Treatment with ZnO-NPs and drug conjugates exhibited minimal cytotoxicity against human cell lines. Human cells were grown in 96 well plate up to $80-90 \%$ confluency as discussed in material and methods. Next, cells monolayer was challenged with drugs-NPs combinations for $24 \mathrm{~h}$ at $37^{\circ} \mathrm{C}$ in humidified conditions with $5 \% \mathrm{CO}_{2}$. Cells alone in RPMI was taken as negative control. The data are representative of several experiments performed in duplicate and expressed as the mean \pm standard error, where $\left(^{*}\right)$ represent when $P \leq 0.05$. Data was analyzed using Graph Pad Prism software $(8.0 .2)$

loaded with $\beta$-cyclodextrin and five drugs (Quericitin, Ceftrixon, Naranjin, Amphotericin B and Ampicillin). These formulations were characterized using a range of techniques such as zeta potential analysis and zeta sizer, UV-visible, FTIR, AFM as previously described (Gagoś and Arczewska 2010; Ethiraj et al. 2014; Catauro et al. 2015; Liu et al. 2015; Diaz-Uribe et al. 2016; Kalaiselvi et al. 2016; Kavitha et al. 2017; Mushtaq et al. 2017; Reddy et al. 2020; Kadam et al. 2020; Kaur et al. 2020; Yang et al. 2020; Sathishkumar et al. 2021). $\mathrm{ZnO}-\mathrm{NPs}$ were synthesized using direct precipitation method and upon successful formation coupled with $\beta$-cycldextrin. Here for first time, we have conjugated $\mathrm{ZnO}-\mathrm{NPs}$ with these drugs and evaluated for their antibacterial properties against a panel of Gram-positive and Gram-negative bacteria. ZnO-NPs exhibited broad spectrum antibacterial activities against clinical isolates tested in this study which is supported by prvious study (Jones et al. 2008). E. coli showed resistance towards ampicillin and cephalosporins (Jacoby 2009; Uzunović-Kamberović et al. 2010; Mendoza-Palomar et al. 2017). E. coli also showed resistance to naringenin (metabolite of naringin) rich compounds (Agus et al. 2017). S. marcescens are thought to show resistance against all cephalosporin including ceftriaxone (Sleigh 1983). Similarly, P. aeruginosa exhibited resistance against ceftriaxone (cephalosporin) and ampicillin (Lamb et al. 2002; Rafailidis et al. 2007; Khatoon et al. 2019). MRSA harbour $m e c A$ gene which is key factor in resistance against ampicillin (Rafailidis et al. 2007). However, by conjugating these drugs with $\mathrm{ZnO}$ NPs, the antibacterial effects were significantly enhanced against tested bacteria. ZnO-NPs possess large surface area with small size that enable NPs to exhibit profound antibacterial activity. It is also believed that NPs trigger the reactive oxygen species (ROS), thus affecting bacterial cell integrity (Sirelkhatim et al. 2015). ZnO-NPs and their nanocomposites with drugs were evaluted for their $\mathrm{MIC}_{50}$ against a range of Gram-positive and Gram-negative bacteria. Souza et al. (2019) also identified MIC values of $\mathrm{ZnO}-\mathrm{NPs}$ and nanoconjugates against food-borne pathogenic bacteria and found them effective (Souza et al. 2019). Similarly, Emami-Karvani and Chehrazi (2011) determined the MIC of ZnO-NPs against $E$. coli and $S$. aureus. The antibacterial effects were higher against $S$. aureus and lower against E. coli (Emami-Karvani and Chehrazi 2011).

Notably, two antibiotics, Ceftriaxone and Ampicillin are presently used to treat various types of bacterial infections. Ceftriaxone is a broad-spectrum cephalosporin antibiotic used currently for the treatment of bacterial infections in various locations, such as in the respiratory tract, skin, soft tissue, and urinary tract. The mode of action involves inhibition of bacterial cell wall synthesis. Similarly, Ampicillin is used currently to treat various types of bacterial infections including respiratory and urinary tracts. It inhibits cell wall synthesis by targeting transpeptidase, leading to cell lysis. Our findings are promising, in that, the efficacy of both antibiotics can be enhanced by conjugation with $\mathrm{ZnO}$ NPs. As the pharmacokinetic and pharmacodynamic profiles of both antibiotics are well established, it is logical to test these compounds and determine their translational value and it is the subject of future studies. In addition, future research will determine whether the aforementioned conjugated antibiotics can overcome increasingly resistant strains of bacteria.

Notably, ZnO-NPs and drug conjugated ZnO-NPs showed minimal cytotoxic effects against human cell lines. Our results are in the agreement with previously published data. For example, Colon et al. (2006) reported that $\mathrm{ZnO}-\mathrm{NPs}$ exhibited negligible cytotoxic activities against human cell lines (Colon et al. 2006). Similarly, El-Waseif (2019) reported ZnO NPs as nontoxic against vero cell lines below $300 \mu \mathrm{g} / \mathrm{mL}$ (El-Waseif 2019). In other studies, $\mathrm{ZnO}$-NPs showed significant anticancer activity against human adinocarcinnoma (MCF-7) (Prashanth et al. 2015; Anitha et al. 2018). Taken together, the present study revealed that $\mathrm{ZnO}$ NPs and drugs-loaded ZnO-NPs exhibited promising antibacterial activities against the MDR Gram-positive and Gram-negative bacteria. The NPs and their drugs conjugates showed concetration-dependant bactericidal activities. Finally, NPs showed negligible 
cytotoxicty against human cell line suggesting their potenial applications as effective chemotherapeutic candidates against infections caused by MDR bacteria.

\section{Supplementary Information}

The online version contains supplementary material available at https://doi. org/10.1186/s13568-021-01261-1.

Additional file 1: Figure S1. Chemical structure of drugs (a) quercetin (QT), (b) naringin (NAR), (c) ceftriaxone (CFT), (d) ampicillin (AMP) and (e) amphotericin B (AMB). Figure S2. Calibration curve of quercetin (QT). Figure S3. Calibration curve of naringin (NAR). Figure S4. Calibration curve of ceftriaxone (CFT). Figure S5. Calibration curve of ampicillin (AMP). Figure S6. Calibration curve of amphotericin B (AMB).

\section{Acknowledgements}

Not applicable.

\section{Authors' contributions}

RS, and NAK conceived the study amid discussion with MRS. NA and ZA conducted all investigations and data analysis under the supervision of NAK, RS and MRS. NA and ZA wrote the first draft. RS and NAK finalized the manuscript. All authors read and approved the final manuscript.

\section{Funding}

This research was funded by the American University of Sharjah and University of Sharjah.

\section{Availability of data and materials}

All relevant data and material is given in the manuscript.

\section{Declarations}

Ethics approval and consent to participate

This article does not contain any studies with human participants. This article does not contain any studies involving animals.

\section{Consent for publication}

Not applicable.

\section{Competing interests}

Authors declare no conflict of interest.

\section{Author details}

${ }^{1}$ College of Arts and Sciences, American University of Sharjah, University City, 26666 Sharjah, United Arab Emirates. ${ }^{2}$ International Centre for Chemical and Biological Sciences, H.E.J. Research Institute of Chemistry, University of Karachi, Karachi 75270, Pakistan. ${ }^{3}$ Department of Clinical Sciences, College of Medicine, University of Sharjah, University City, 27272 Sharjah, United Arab Emirates.

Received: 27 June 2021 Accepted: 29 June 2021

Published online: 10 July 2021

\section{References}

Agus S, Achmadi SS, Mubarik NR (2017) Antibacterial activity of naringeninrich fraction of pigeon pea leaves toward Salmonella thypi. Asian Pac Trop Biomed 7(8):725-728

Akbar N, Siddiqui R, labal M, Sagathevan K, Khan NA (2018) Gut bacteria of cockroaches are a potential source of antibacterial compound(s). Lett Appl Microbiol 66:416-426

Akbar N, Siddiqui R, labal M, Khan NA (2020) Antibacterial activities of selected pure compounds isolated from gut bacteria of animals living in polluted environments. Antibiotics 9(4):190
Akbar N, Khan NA, Sagathevan K, lqbal M, Tawab A, Siddiqui R (2019) Gut bacteria of Cuora amboinensis (turtle) produce broad-spectrum antibacterial molecules. Sci Rep 9:1-19

Ambekar M, Mohsina S, Sharma V (2015) Development and validation of simultaneous estimation of sulbactum and ampicillin (Sultamicillin). Panacea J Pharm Pharm Sci 4(3):601-616

Anitha R, Ramesh KV, Ravishankar TN, Kumar KS, Ramakrishnappa T (2018) Cytotoxicity, antibacterial and antifungal activities of $\mathrm{ZnO}$ nanoparticles prepared by the Artocarpus gomezianus fruit mediated facile green combustion method. J Sci Adv Mat Dev 3(4):440-451

Anwar A, Khalid S, Perveen S, Ahmed S, Siddiqui R, Khan NA, Shah MR (2018) Synthesis of 4-(dimethylamino) pyridine propylthioacetate coated gold nanoparticles and their antibacterial and photophysical activity. J Nanobiotechnol 16(1):1-8

Azam A, Ahmed AS, Oves M, Khan MS, Habib SS, Memic A (2012) Antimicrobial activity of metal oxide nanoparticles against Gram-positive and Gram-negative bacteria: a comparative study. Int J Nanomed 7:6003

Blair JM, Webber MA, Baylay AJ, Ogbolu DO, Piddock LJ (2015) Molecular mechanisms of antibiotic resistance. Nat Rev Microbiol 13:42-51

Catauro M, Papale F, Bollino F, Piccolella S, Marciano S, Nocera P, Pacifico S (2015) Silica/quercetin sol-gel hybrids as antioxidant dental implant materials. Sci Technol Adv Mater 16(3):035001

Colon G, Ward BC, Webster TJ (2006) Increased osteoblast and decreased Staphylococcus epidermidis functions on nanophase $\mathrm{ZnO}$ and $\mathrm{TiO}_{2}$. Biomed Mater Res A 78(3):595-604

Davis ME, Brewster ME (2004) Cyclodextrin-based pharmaceutics: past, present and future. Nat Rev Drug Discov 3(12):1023-1035

Diaz-Uribe CE, Vallejo W, Oliveros G, Muñoz A (2016) Study of scavenging capacity of naringin extracted from Citrus uranium peel against free radicals. Prospectiva 14(2):31-35

Ebrahimi S, Farhadian N, Karimi M, Ebrahimi M (2020) Enhanced bactericidal effect of ceftriaxone drug encapsulated in nanostructured lipid carrier against gram-negative Escherichia coli bacteria: drug formulation, optimization, and cell culture study. Antimicrob Resist Infect Control $9(1): 1-12$

El-Waseif AA (2019) Cytotoxicity and antimicrobial activity of naturally and chemically synthesized zinc oxide nanoparticles. JASMR 14(1):42

Emami-Karvani Z, Chehrazi P (2011) Antibacterial activity of ZnO nanoparticle on Gram-positive and Gram-negative bacteria. Afr J Microbiol Res 5(12):1368-1373

Ethiraj R, Thiruvengadam E, Sampath VS, Vahid A, Raj J (2014) Development and validation of stability indicating spectroscopic method for content analysis of Ceftriaxone sodium in Pharmaceuticals. Int Sch Res Not 2014:1-5

Gagoś M, Arczewska M (2010) Spectroscopic studies of molecular organization of antibiotic amphotericin B in monolayers and dipalmitoylphosphatidylcholine lipid multibilayers. Biochim Biophys Acta Biomembr 1798(11):2124-2130

Ghorbani HR, Mehr FP, Pazoki H, Rahmani BM (2015) Synthesis of ZnO nanoparticles by precipitation method. Orient J Chem 31(2):1219-1221

Grela E, Zdybicka-Barabas A, Pawlikowska-Pawlega B, Cytrynska M, Wlodarczyk M, Grudzinski W, Luchowski R, Gruszecki WI (2019) Modes of the antibiotic activity of amphotericin B against Candida albicans. Sci Rep $9(1): 1-10$

Gunasekaran S, Charles J (2008) Spectral measurements and qualitative analysis of ceftriaxone and cefotaxime. Asian J Chem 20(2):1343

Guzman M, Dille J, Godet S (2012) Synthesis and antibacterial activity of silver nanoparticles against Gram-positive and Gram-negative bacteria. Nanomed Nanotech Biol Med 8(1):37-45

Habash MB, Goodyear MC, Park AJ, Surette MD, Vis EC, Harris RJ, Khursigara CM (2017) Potentiation of tobramycin by silver nanoparticles against Pseudomonas aeruginosa biofilms. Antimicrob Agents Chemother 61(11):e00415-417

Habash MB, Park AJ, Vis EC, Harris RJ, Khursigara CM (2014) Synergy of silver nanoparticles and aztreonam against Pseudomonas aeruginosa PAO1 biofilms. Antimicrob Agents Chemother 58(10):5818-5830

Hathout RM, Abdelhamid SG, El-Housseiny GS, Metwally AA (2020) Comparing cefotaxime and ceftriaxone in combating meningitis through nose-tobrain delivery using bio/chemoinformatics tools. Sci Rep 10(1):1-7 Jacoby GA (2009) AmpC beta-lactamases. Clin Microbiol Rev 22(1):161-182 
Jones N, Ray B, Ranjit KT, Manna AC (2008) Antibacterial activity of ZnO nanoparticle suspensions on a broad spectrum of microorganisms. FEMS Microbiol Lett 279(1):71-76

Kadam W, Balakrishnan RM, Ettiyappan JP (2020) Fluorometric detection of bisphenol A using $\beta$-cyclodextrin-functionalized $\mathrm{ZnO}$ QDs. Environ Sci Pollut Res. https://doi.org/10.1007/s11356-020-07797-2

Kalaiselvi A, Roopan SM, Madhumitha G, Ramalingam C, Al-Dhabi NA, Arasu MV (2016) Catharanthus roseus-mediated zinc oxide nanoparticles against photocatalytic application of phenol red under UV@ 365 nm. Curr Sci 111(11):1811-1815

Kaushik D, Mohan M, BoraDe DM, Swami OC (2014) Ampicillin: rise fall and resurgence. J Clin Diagn Res 8(5):ME01

Kaur A, Preet S, Kumar V, Kumar R, Kumar R (2019) Synergetic effect of vancomycin loaded silver nanoparticles for enhanced antibacterial activity. Colloids Surf b Bioint 176:62-69

Kaur K, Kumar P, Kush P (2020) Amphotericin B loaded ethyl cellulose nanoparticles with magnified oral bioavailability for safe and effective treatment of fungal infection. Biomed Pharmacother 128:110297

Kavitha S, Dhamodaran M, Prasad R, Ganesan M (2017) Synthesis and characterisation of zinc oxide nanoparticles using terpenoid fractions of Andrographis paniculata leaves. Int Nano Lett 7(2):141-147

Khameneh B, Diab R, Ghazvini K, Bazzaz BSF (2016) Breakthroughs in bacterial resistance mechanisms and the potential ways to combat them. Microb Pathog 95:32-42

Khatoon N, Alam H, Khan A, Raza K, Sardar M (2019) Ampicillin silver nanoformulations against multidrug resistant bacteria. Sci Rep 9(1):1-10

Kumar S, Bhanjana G, Kumar A, Taneja K, Dilbaghi N, Kim KH (2016) Synthesis and optimization of ceftriaxone-loaded solid lipid nanocarriers. Chem Phys Lipids 200:126-132

Lamb HM, Ormrod D, Scott LJ, Figgitt DP (2002) Ceftriaxone. Drugs 62(7):1041-1089

Ling LL, Schneider T, Peoples AJ, Spoering AL, Engels I, Conlon BP, Mueller A, Schäberle TF, Hughes DE, Epstein S (2015) A new antibiotic kills pathogens without detectable resistance. Nature 517:455-459

Liu D, Pan H, He F, Wang X, Li J, Yang X, Pan W (2015) Effect of particle size on oral absorption of carvedilol nanosuspensions: in vitro and in vivo evaluation. Int J Nanomed 10:6425

Mendoza-Palomar N, Balasch-Carulla M, González-Di Lauro S, Céspedes MC, Andreu A, Frick MA, Linde MÁ, Soler-Palacin P (2017) Escherichia coli earlyonset sepsis: trends over two decades. Eur J Pediatr 176(9):1227-1234

Mukheem A, Muthoosamy K, Manickam S, Sudesh K, Shahabuddin S, Saidur R, Akbar N, Sridewi N (2018) Fabrication and characterization of an electrospun PHA/graphene silver nanocomposite scaffold for antibacterial applications. Materials 11(9):1673

Munita JM, Arias CA (2016) Mechanisms of antibiotic resistance. Vir Mech Bac Pathog. https://doi.org/10.1128/9781555819286.ch17

Mushtaq S, Khan JA, Rabbani F, Latif U, Arfan M, Yameen MA (2017) Biocompatible biodegradable polymeric antibacterial nanoparticles for enhancing the effects of a third-generation cephalosporin against resistant bacteria. J Med Microbiol 66(3):318-327

Nagaraju G, Prashanth SA, Shastri M, Yathish KV, Anupama C, Rangappa D (2017) Electrochemical heavy metal detection, photocatalytic, photoluminescence, biodiesel production and antibacterial activities of Ag-ZnO nanomaterial. Mater Res Bull 94:54-63

Prasad K, Lekshmi GS, Ostrikov K, Lussini V, Blinco J, Mohandas M, Vasilev K, Bottle S, Bazaka K, Ostrikov K (2017) Synergic bactericidal effects of reduced graphene oxide and silver nanoparticles against Gram-positive and Gram-negative bacteria. Sci Rep 7(1):1-11

Prashanth GK, Prashanth PA, Bora U, Gadewar M, Nagabhushana BM, Ananda S, Krishnaiah GM, Sathyananda HM (2015) In vitro antibacterial and cytotoxicity studies of $\mathrm{ZnO}$ nanopowders prepared by combustion assisted facile green synthesis. KIJOMS 1(2):67-77

Rafailidis PI, loannidou EN, Falagas ME (2007) Ampicillin/sulbactam. Drugs 67(13):1829-1849

Raoufi D (2013) Synthesis and microstructural properties of $\mathrm{ZnO}$ nanoparticles prepared by precipitation method. Renew Energy 50:932-937

Rachmawati H, Edityaningrum CA, Mauludin R (2013) Molecular inclusion complex of curcumin- $\beta$-cyclodextrin nanoparticle to enhance curcumin skin permeability from hydrophilic matrix gel. AAPS PharmSciTech 14(4):1303-1312

Reddy CK, Jung ES, Son SY, Lee CH (2020) Inclusion complexation of catechinsrich green tea extract by $\beta$-cyclodextrin: Preparation, physicochemical, thermal, and antioxidant properties. LWT 131:09723

Ren J, Zhang R, Regenstein JM (2017) Adding biological function to nonbiological nanoparticles. Nutr Deliv. https://doi.org/10.1016/B978-0-12804304-2.00013-5

Sathishkumar P, Li Z, Govindan R, Jayakumar R, Wang C, Gu FL (2021) Zinc oxide-quercetin nanocomposite as a smart nano-drug delivery system: Molecular-level interaction studies. Appl Surf Sci 536:147741

Sawant VJ, Bamane SR (2018) PEG-beta-cyclodextrin functionalized zinc oxide nanoparticles show cell imaging with high drug payload and sustained $\mathrm{pH}$ responsive delivery of curcumin in to MCF-7 cells. J Drug Deliv Sci Technol 43:397-408

Seil JT, Webster TJ (2012) Antimicrobial applications of nanotechnology: methods and literature. Int J Nanomed 7:2767

Sirelkhatim A, Mahmud S, Seeni A, Kaus NHM, Ann LC, Bakhori SKM, Hasan H, Mohamad D (2015) Review on zinc oxide nanoparticles: antibacterial activity and toxicity mechanism. Nanomicro Lett 7(3):219-242

Sleigh JD (1983) Antibiotic resistance in Serratia marcescens. BMJ 287(6406):1651

Souza RCD, Haberbeck LU, Riella HG, Ribeiro DH, Carciofi BA (2019) Antibacterial activity of zinc oxide nanoparticles synthesized by solochemical process. Braz J Chem Eng 36(2):885-893

Souza VGL, Rodrigues C, Valente S, Pimenta C, Pires JRA, Alves MM, Santos CF, Coelhoso IM, Fernando AL (2020) Eco-friendly ZnO/Chitosan bionanocomposites films for packaging of fresh poultry meat. Coatings 10(2):110

Srinivasan R, Devi KR, Santhakumari S, Kannappan A, Chen X, Ravi AV, Lin X (2020) Anti-quorum sensing and protective efficacies of naringin against Aeromonas hydrophila infection in Danio rerio. Front Microbiol 11:3087

Ssekatawa K, Byarugaba DK, Kato CD, Ejobi F, Tweyongyere R, Lubwama M, Kirabira JB, Wampande EM (2020) Nanotechnological solutions for controlling transmission and emergence of antimicrobial-resistant bacteria, future prospects, and challenges: a systematic review. J Nanoparticle Res 22(5):1-30

Tamboli DP, Lee DS (2013) Mechanistic antimicrobial approach of extracellularly synthesized silver nanoparticles against gram positive and gram negative bacteria. J Hazard Mater 260:878-884

Tipper DJ (1985) Mode of action of $\beta$-lactam antibiotics. Pharmacol Ther 27(1):1-35

Uzunović-Kamberović S, Odobašić M, Husković A, Hutinović A, Ibranović $\mathrm{N}$ (2010) Antibiotic resistance of coliform bacteria from communityacquired urinary tract infections in the Zenica-Doboj Canton. Bosnia Herzegovina Med Glas 7(1):40-45

Vandermeulen G, Rouxhet L, Arien A, Brewster ME, Préat V (2006) Encapsulation of amphotericin B in poly (ethylene glycol)-block-poly ( $\boldsymbol{\varepsilon}$-caprolactone-co-trimethylenecarbonate) polymeric micelles. Int J Pharm 309(1-2):234-240

Wang L, Hu C, Shao L (2017) The antimicrobial activity of nanoparticles: present situation and prospects for the future. Int J Nanomed 12:1227

Wang S, Yao J, Zhou B, Yang J, Chaudry MT, Wang M, Xiao F, Li Y, Yin W (2018) Bacteriostatic effect of quercetin as an antibiotic alternative in vivo and its antibacterial mechanism in vitro. J Food Prot 81(1):68-78

Yang Y, Tao B, Gong Y, Chen R, Yang W, Lin C, Chen M, Qin L, Jia Y, Cai K (2020) Functionalization of Ti substrate with $\mathrm{pH}$-responsive naringin- $\mathrm{ZnO}$ nanoparticles for the reconstruction of large bony after osteosarcoma resection. J Biomed Mater Res A 108(11):2190-2205

Yusof NAA, Zain NM, Pauzi N (2019) Synthesis of ZnO nanoparticles with chitosan as stabilizing agent and their antibacterial properties against Grampositive and Gram-negative bacteria. Int J Biol Macromol 124:1132-1136

\section{Publisher's Note}

Springer Nature remains neutral with regard to jurisdictional claims in published maps and institutional affiliations. 